
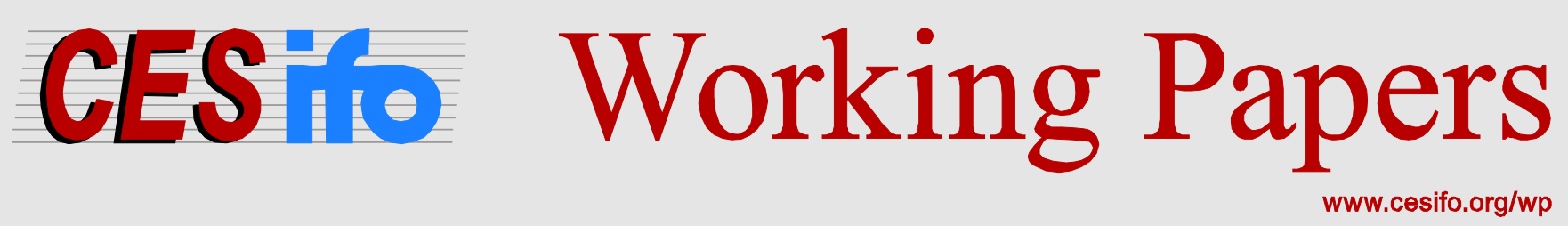

\title{
Dimensions of Macroeconomic Uncertainty: A Common Factor Analysis
}

\author{
Steffen R. Henzel \\ Malte Rengel
}

\author{
CESIFO WORKING PAPER NO. 4991 \\ CATEgORY 6: FiscAl POLICY, MACROECONOMICS AND GROWTH \\ SEPTEMBER 2014
}

An electronic version of the paper may be downloaded

- from the SSRN website:

- from the RePEc website:

- from the CESifo website:

wWW.SSRN.com

Www.RePEc.org

www.CESifo-group.org/wp 


\title{
Dimensions of Macroeconomic Uncertainty: A Common Factor Analysis
}

\begin{abstract}
Uncertainty about the future course of the economy is a possible driver of aggregate fluctuations. To identify the different dimensions of uncertainty in the macroeconomy we construct a large dataset covering all types of economic uncertainty. We then identify two fundamental factors which account for the common dynamics in this dataset. These factors are interpreted as macroeconomic uncertainty. The first factor mainly captures business cycle uncertainty while the second factor is identified as oil and commodity price uncertainty. While both types of uncertainty foreshadow a decline in output, surprise increases in oil and commodity price uncertainty appear to be more important for fluctuations in real activity.
\end{abstract}

JEL-Code: C320, C380, E320.

Keywords: macroeconomic uncertainty, factor model, aggregate fluctuations.

\author{
Steffen R. Henzel \\ Ifo Institute - Leibniz Institute for \\ Economic Research \\ at the University of Munich \\ Poschingerstrasse 5 \\ Germany-81679 Munich \\ Henzel@ifo.de
}

\author{
Malte Rengel \\ Department of Economics \\ University of Göttingen \\ Göttingen / Germany \\ mrengel@uni-goettingen.de
}

September 12, 2014

(first version: May 15, 2012)

We would like to thank Rüdiger Bachmann, Kai Carstensen, Helmut Herwartz and the participants of the workshop on 'Uncertainty and forecasting in macroeconomics' in Eltville, June 2012, the workshop on 'High dimensional time series in macroeconomics and finance' in Vienna, May 2013, and the $28^{\text {th }}$ Annual Congress of the European Economic Association in Gothenburg, August 2013 for very valuable comments and suggestions. Financial support from the German Research Foundation (Grant No. CA 833/2 and HE 2188/3-1) is gratefully acknowledged. The first version of the paper circulated under the title: Common uncertainty factors. 


\section{Introduction}

Uncertainty about the future course of the economy is identified as a potential driving force behind business cycle fluctuations in recent research (see Bloom, 2009; Alexopoulos and Cohen, 2009; Knotek II and Khan, 2011; Bachmann, Elstner, and Sims, 2013, among others). However, many different dimensions of uncertainty are considered in the economic literature. ${ }^{1}$ In fact, time varying uncertainty surrounds the movements of almost all macroeconomic variables (Gonçalves and Kilian, 2004). Policy makers and researchers thus face a monitoring and decision problem pertaining to the different types of uncertainty prevailing in the macroeconomy.

In this paper, we provide an empirical justification for the number of fundamental second moment shocks in the macroeconomy. We analyze a large dataset in the spirit of Giannone, Reichlin, and Sala (2004) which consists of 164 individual uncertainty measures covering all types of economic uncertainty. Using a dynamic factor model, we identify the fundamental factors that have an impact on the bulk of these uncertainty measures and interpret them as different types of macroeconomic uncertainty. ${ }^{2}$ Such a definition of macroeconomic uncertainty is similar to Jurado, Ludvigson, and $\mathrm{Ng}$ (2014) who independently proposed a factor based approach to measure uncertainty. However, Jurado et al. (2014) focus on the factor with the largest explanatory power, whereas the identification and disentanglement of different fundamental types of macroeconomic uncertainty is at the core of our study.

A large body of literature on factor models documents that there are only a handful of fundamental first moment shocks which are relevant for explaining the business cycle (see Sargent and Sims, 1977; Forni and Reichlin, 1998; Stock and Watson, 2002; Giannone et al., 2004, among others). Since the number of fundamental shocks contained in a factor model is typically much smaller than the number of variables in the dataset, factor models provide a justification for the modeling strategy underlying modern business cycle models. Recent studies enhance business cycle models with shocks to second moments and analyze their role for business cycle fluctuations, for instance, during the recent global financial crisis (Gilchrist, Sim, and Zakrajšek, 2014; Born and

\footnotetext{
${ }^{1}$ Among many others, Friedman (1977) and Ball (1992) discuss the effects of inflation uncertainty. Furthermore, Ramey and Ramey (1995), Grier and Perry (2000) are concerned with the effects of production uncertainty. Born and Pfeifer (2013), Fernández-Villaverde, Guerrón-Quintana, Kuester, and RubioRamírez (2013), and Baker, Bloom, and Davis (2013) model policy uncertainty. Oil price uncertainty is analyzed by, for instance, Elder and Serletis (2010).

${ }^{2}$ Note that macroeconomic uncertainty relates to aggregate shocks, as opposed to idiosyncratic (e.g. firm-specific) uncertainty which results from the dispersion of idiosyncratic shocks which themselves average out over many units (e.g. firms).
} 
Pfeifer, 2013; Arellano, Bai, and Kehoe, 2012; Fernández-Villaverde, Guerrón-Quintana, Rubio-Ramírez, and Uribe, 2011; Basu and Bundick, 2012; Bloom, Floetotto, Jaimovich, Saporta-Eksten, and Terry, 2012; Schaal, 2012; Bachmann and Bayer, 2013). Our study contributes by providing some guidance how many shocks are important for the fluctuations of uncertainty at the macroeconomic level.

Our results provide evidence that macroeconomic uncertainty in the US economy is driven by two fundamental shocks. We document that the first fundamental shock triggers uncertainty associated with demand related variables such as aggregate production and capacity utilization. We thus identify the corresponding factor as 'business cycle uncertainty'. The second fundamental shock mainly affects uncertainty associated with supply related variables such as oil and commodity prices, and we interpret the related factor as 'oil and commodity price uncertainty'. Moreover, it can be shown that the indicators for business cycle uncertainty and oil and commodity price uncertainty, which we obtain from the factor approach, peak at business cycle and oil-market related events, respectively. We document that the factor-based measure of Jurado et al. (2014) appears to combine both types of macroeconomic uncertainty. Moreover, there are nonnegligible differences between macroeconomic uncertainty and financial market uncertainty which is often used as a proxy for aggregate economic uncertainty (Bloom, 2009; Basu and Bundick, 2012; Gilchrist et al., 2014, among others). We also demonstrate that uncertainty about economic policy put forward by Baker et al. (2013) is closely related to business cycle uncertainty but not to oil and commodity price uncertainty.

Impulse response analysis reveals that both types of macroeconomic uncertainty foreshadow a drop in real activity, i.e. both types of macroeconomic uncertainty are countercyclical. However, both types of uncertainty have different quantitative implications for real activity. While the decline following a surprise increase in business cycle uncertainty is not very pronounced, we document a larger and more persistent effect for oil and commodity price uncertainty. Such a finding suggests that unforeseen shifts in oil and commodity price uncertainty appear to be more important for business cycle fluctuations than those in business cycle uncertainty.

The remainder of the paper is structured as follows. In section 2, we introduce the dataset, and section 3 explains how we measure macroeconomic uncertainty by means of a dynamic factor model. The number of fundamental uncertainty factors is analyzed in section 4 where we also give an interpretation of the factors and provide a comparison to alternative uncertainty measures. In the remainder of section 4 we analyze how macroeconomic uncertainty relates to economic activity. The paper concludes in section 5 . 


\section{The dataset}

We use a large-scale monthly dataset as in Giannone et al. (2004) which is commonly employed to describe the development of the US economy over the business cycle (see also Stock and Watson, 2002). The data can be split up into 14 categories: industrial production, capacity utilization, employment, sales and consumption, housing and construction, inventories, new and unfilled orders, financial variables, interest rates, monetary variables, prices, wages, merchandise ex- and imports, business outlook. Our analysis is based on data covering the period 1970M1 to 2011M4. During the considered period, the Federal Reserve has undertaken a number of unconventional policy measures ('quantitative easing') leading to severe outliers in monetary aggregates distorting the estimation of uncertainty later on. Hence, we exclude the monetary base (series 117 in table A.1), the depository institutions reserves (series 118-119) and the loans and securities at all commercial banks (series 125). Further, consistent data for the commercial paper outstanding (series 104), the delinquency rate on bank-held consumer installment loans (series 126), and the index of sensitivity materials prices (series 132) are not available. This leaves us with $n=164$ variables which are transformed to achieve stationarity. ${ }^{3}$

\section{Measuring macroeconomic uncertainty}

\subsection{Individual uncertainty measures}

In what follows we define macroeconomic uncertainty as the common dynamics of uncertainty from a broad range of variables which are all surrounded by time varying uncertainty. To be able to measure macroeconomic uncertainty, it is thus necessary to measure the latent variable specific uncertainty first. For this purpose we rely on the time-series dimension of individual economic variables since a direct measure of uncertainty is not available. ${ }^{4}$ A typical measure of uncertainty in this context is the conditional volatility of GARCH models which can be interpreted as (in-sample) forecast

\footnotetext{
${ }^{3}$ A detailed list of single series and a description of the transformations are provided in table A.1 in the appendix.

${ }^{4}$ The literature discusses several alternative approaches to measure uncertainty such as the dispersion of forecasts collected in surveys. A direct measure would be the average standard deviation of subjective probability distributions, for instance, polled in the Survey of Professional Forecasters (see Zarnowitz and Lambros, 1987; Giordani and Söderlind, 2003; Rich and Tracy, 2010, among others). However, surveys are limited to selected variables such as GDP, GDP deflator, and CPI inflation.
} 
uncertainty (see Baillie, Chung, and Tieslau, 1996; Grier and Perry, 1998; Lahiri and Sheng, 2010; Grimme, Henzel, and Wieland, 2014, among others). ${ }^{5}$ As an alternative to GARCH models, stochastic volatility (SV) models are often used since they involve an additional independent shock impinging on the time-varying second moments of a process which lends itself to an economic interpretation (see Fernández-Villaverde and Rubio-Ramírez, 2010, for a discussion). SV models are therefore extensively applied in the recent empirical macroeconomic literature studying time varying second moments (Fernández-Villaverde, Guerrón-Quintana, and Rubio-Ramírez, 2010; Born and Pfeifer, 2013; Fernández-Villaverde et al., 2013; Jurado et al., 2014).

However, the calculation of GARCH and SV measures necessitates an explicit formulation of a (parametric) data generating process. Note that we consider a multitude of time series, and to meet the specific requirements of a certain variable innumerable extensions of the basic GARCH and SV model have been proposed. Moreover, to avoid misspecification errors, each model would have to pass a battery of specification tests (Lundbergh and Teräsvirta, 2002). We therefore consider a data driven filter to approximate the conditional volatility which is known as the 'RiskMetrics' procedure (Morgan, 1996) and which is a robust alternative to GARCH and SV models. The objective is to calculate an exponentially weighted moving average of the squared (in-sample) forecast errors of an appropriately defined forecast model.

We follow Stock and Watson (2002) where the variable of interest $y_{t}$ is forecast using an autoregressive model augmented with predictions of common factors $\hat{g}_{t+1 \mid t}$ which summarize the dynamics of a large cross section of variables ${ }^{6}$

$$
y_{t+1}=\alpha_{0}+\sum_{j=1}^{M} \alpha_{j} \hat{g}_{t-j+2 \mid t-j+1}+\sum_{j=1}^{P} \beta_{j} y_{t-j+1}+e_{t+1}
$$

The (in-sample) forecast error is given by $e_{t+1}$. Adding factors ensures that predictions are based on a large information set which prevents an overestimation of the uncertainty surrounding the forecast (see Jurado et al., 2014, for a similar argument). Estimates of the factors are obtained from a parametric dynamic factor model. The specification of the dynamic factor model follows common practice in the forecasting literature (see, for instance, Kose, Otrok, and Whiteman, 2003; Bańbura, Giannone, and Reichlin, 2011)

\footnotetext{
${ }^{5}$ Moreover, measures of conditional volatility have the advantage that they are not affected by timevarying risk aversion as opposed to observable indicators of financial market risk such as the optionbased CBOE implied volatility index (see Bekaert, Hoerova, and Lo Duca, 2013, for a discussion).

${ }^{6}$ To simplify notation we suppress the index of individual variables in $y_{t}$.
} 
and reads as

$$
\begin{aligned}
& Y_{\mathrm{t}}=\Lambda \mathrm{g}_{\mathrm{t}}+\zeta_{\mathrm{t}} \\
& \mathrm{g}_{\mathrm{t}}=\Psi(\mathrm{L}) \mathrm{g}_{\mathrm{t}-1}+\varepsilon_{\mathrm{t}},
\end{aligned}
$$

where $Y_{t}$ is of dimension $n \times 1$ and collects the variables in our information set. The factors are collected in the $r \times 1$ vector $g_{t}$, and $\Lambda$ is a conformable matrix of factor loadings. Idiosyncratic movements are captured by $\zeta_{t}$. The factors follow a simple vector autoregression with innovations $\varepsilon_{\mathrm{t}}$. We estimate the model with the Quasi Maximum Likelihood procedure proposed by Doz, Giannone, and Reichlin (2012), i.e. we apply an EM algorithm combined with Kalman filtering and smoothing. ${ }^{7}$ Once the model's parameters are estimated using full sample information, the filtered factors $\hat{g}_{t+1 \mid t}$ in (1) are obtained from the Kalman prediction step which processes only information available up to period $t$. Using the filtered factors as opposed to the smoothed ones delivers forecast errors which are closer to those experienced in real time. ${ }^{8}$

During estimation we set the number of factors in (2) to 12 which is what the information criteria of Bai and $\mathrm{Ng}$ (2002) indicate. The lag polynomial $\Psi$ (L) contains four lags. The number of factors in (1) $r$ and the lag orders $M$ and $P$ are determined by means of the BIC in the range of $0 \leqslant r \leqslant 12,1 \leqslant M \leqslant 4$ and $1 \leqslant P \leqslant 6$, respectively. Based on an initial sample beginning in 1968M6 we obtain $\mathrm{T}=496$ (in-sample) forecast errors for each of the 164 variables in our dataset covering the period 1970M1 to 2011M4.

The time-varying uncertainty $\sigma_{t}^{2}$ for each individual series follows

$$
\sigma_{\mathrm{t}}^{2}=\phi \sigma_{\mathrm{t}-1}^{2}+(1-\phi) e_{\mathrm{t}-1}^{2}
$$

As before, $e_{t}$ denotes the one-step ahead forecast error from (1). We implement the 'RiskMetrics' procedure by rewriting (4) as an infinite sum $\sigma_{t}^{2}=(1-\phi) \sum_{i=1}^{\infty} \phi^{i-1} e_{t-i}^{2}$ ' which, in practice, is truncated at $t-1$. To avoid distortions of the uncertainty measure at the beginning of the sample, we apply the adjustment factor $1 /\left(1-\gamma^{t}\right)$ as proposed by Andersen, Bollerslev, Christoffersen, and Diebold (2006). The decay parameter $\phi$

\footnotetext{
${ }^{7}$ A detailed description of the estimation procedure is provided in appendix B.

${ }^{8}$ Notwithstanding, these forecast errors may differ from real time forecast errors since the remaining parameters are estimated using full sample information such that parameter uncertainty tends to be underestimated. Recursive estimation of the factor model in (7) would solve the problem but a substantial part of the sample has to be reserved to initialize the estimation. In a robustness check in appendix $G$ we apply observations form the first five years to initialize recursive model estimates, and demonstrate that, for the remaining years, the measure of macroeconomic uncertainty is almost unaffected by using either in-sample or out-of-sample forecast errors.
} 

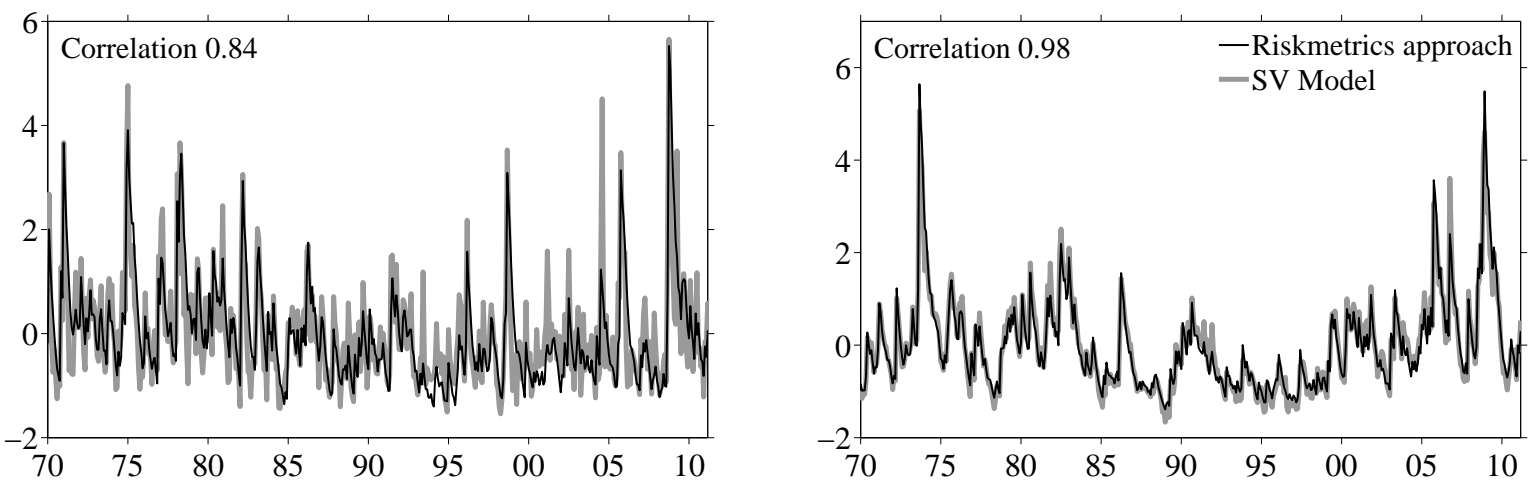

Note: Panels display the SV measures (bold gray lines) and the 'RiskMetrics' measures (thin black lines). To facilitate comparability all measures are demeaned and have a standard deviation of one.

Figure 1: RiskMetrics and SV measures

in (4) governs the smoothness of the variance process. ${ }^{9}$ The thin black lines in figure 1 show the resulting uncertainty measures associated with industrial production (IP) and consumer price inflation (CPI), respectively.

Before we proceed with the measurement of macroeconomic uncertainty we verify whether the uncertainty measures for IP and CPI from the 'RiskMetrics' approach are consistent with a measure obtained from the estimated parametric SV model

$$
\begin{aligned}
e_{t} & =\exp \left(\log \left(\sigma_{t, S V}^{2}\right) / 2\right) \vartheta_{t} \\
\log \left(\sigma_{t, S V}^{2}\right) & =\gamma_{0}+\gamma_{1} \log \left(\sigma_{t-1, S v}^{2}\right)+\omega v_{t}
\end{aligned}
$$

The logarithmic conditional variance in (6) is modeled as a first-order autoregressive process. The innovations $\vartheta_{t}$ and $v_{t}$ are both $N(0,1)$ distributed and mutually independent. We estimate the model using a Maximum Likelihood approach. Due to the nonlinearity of the model we simulate the likelihood function by means of the Efficient Importance Sampler (EIS) (Liesenfeld and Richard, 2003). Given the parameter estimates, we use efficient importance sampling to obtain the filtered variance estimates. The bold gray lines in figure 1 depict the resulting series. SV and 'RiskMetrics' measures co-move closely and their correlation amounts to 0.84 (IP), and 0.98 (CPI), respectively. Overall, individual uncertainty measures are largely unaffected by the procedure used to filter the variance. The 'RiskMetrics' approach appears to be a simple but admissible method

\footnotetext{
${ }^{9}$ We set $\phi=0.7$ implying a half-life period of the innovation $e_{t}$ of approximately two months. As proposed by Morgan (1996) we use the same value for $\phi$ for all series in the considered dataset.
} 
to evaluate the uncertainty surrounding each of the 164 variables in a data-driven and robust manner.

\subsection{Macroeconomic uncertainty measures}

To identify the common dynamics behind the individual uncertainty measures which we interpret as macroeconomic uncertainty we estimate a factor model similar to that used in section 3.1

$$
\begin{aligned}
X_{t} & =\lambda f_{t}+\xi_{t}, \\
f_{t} & =\psi(L) f_{t-1}+\epsilon_{t} .
\end{aligned}
$$

The standardized individual uncertainty measures are collected in the data vector $X_{t}=\left(\log \left(\sigma_{1, t}\right), \ldots, \log \left(\sigma_{n, t}\right)\right)^{\prime}$. We take the logarithmic square root of $\sigma_{i, t}^{2}$ to allow factors to adopt negative values. Macroeconomic uncertainty will be assessed by the kdimensional vector of fundamental factors $f_{t}$ which is responsible for the common dynamics of the individual uncertainty measures. The latter is summarized by means of the common component $X_{t}=\lambda f_{t}$. The remaining unexplained part is governed by the idiosyncratic component $\xi_{t}$ which may be weakly cross-sectionally and serially correlated ('approximate factor model'). Doz et al. (2012) show that the unobserved factors $f_{t}$ of an approximate factor model are estimated consistently if $n$ and $T$ become large even if cross-sectional and serial correlation of the idiosyncratic components is not modeled explicitly. ${ }^{10}$ The factors in (8) follow an autoregressive process where the innovations $\epsilon_{\mathrm{t}}$ can be decomposed into $\epsilon_{\mathrm{t}}=\mathrm{R} \mathrm{u}_{\mathrm{t}}$. The $\mathrm{k}$-dimensional vector $\mathrm{u}_{\mathrm{t}}$ contains orthogonal shocks and $\mathrm{R}$ is a $\mathrm{k} \times \mathrm{k}$ conformable matrix. We assume that the number of shocks $u_{t}$ is identical to the number of common factors $k$, i.e. $f_{t}$ follows a vector autoregression. Later on we make use of the model structure to identify and interpret each of the common factors separately. Since $k \ll n$ the number of fundamental shocks $k$ identifies the reduced dimension of the dataset.

As in section 3.1 we estimate the model (7) to (8) using the methods in Doz et al. (2012). The lag order implied by $\psi(\mathrm{L})$ is six which should be sufficient to capture the dynamics of the data.

\footnotetext{
${ }^{10} \mathrm{As}$ a robustness check we allow the idiosyncratic processes to follow a first order autoregressive process and estimate the model based on the generalisation of Bańbura and Modugno (2012). The pairwise correlations of the factors from both models are all greater than 0.98 .
} 


\section{Estimation results}

\subsection{The number of common uncertainty factors}

In the following, we aim at unraveling the number of fundamental shocks which have an impact on a broad range of the individual uncertainty measures. First, we consider the explained variance proportion $\left(R^{2}\right)$ of the estimated factor model in (7) and (8) for the aggregate dataset which results for different numbers of dynamic factors $k$. The model with one factor explains $18 \%$ of the variation. The gain in explained variance by adding a second factor is $8 \%$ while the third factor adds about $6 \%$, and the fourth factor adds $4 \%$. Overall, the gain of an additional factor decreases relatively fast suggesting not more than four common factors.

In figure 2 we display the explained variance proportion $\left(R^{2}\right)$ for each individual uncertainty measure. In the upper panel grey bars indicate $R^{2}$ when $k=1$. In this specification the common component has explanatory power mainly for the uncertainty associated with most production variables, capacity utilization and some employment variables. However, the explanatory power for other uncertainty measures, especially those of most price variables, is relatively low. One factor thus appears to be insufficient to capture the common dynamics of uncertainty. Consequently, we introduce a second fundamental factor and calculate the individual $R^{2}$ for this model specification which is represented by means of the crossed line in the upper panel of figure 2. As a result, the variance proportion which is explained by the common component improves for a broad range of uncertainty variables. Particularly, many price related uncertainty measures experience an increase in $\mathrm{R}^{2}$. In the lower panel of figure 2 we display the effect of adding a third factor to the model. An improvement in terms of $R^{2}$ appears only for a rather narrow group of individual measures of uncertainty surrounding shortterm interest rates (variables 105 to 108). Since the third factor does not add much to the common dynamics, we conclude that it does not represent macroeconomic uncertainty. The number of common factors thus appears to be two.

Particularly, two common shocks explain a large fraction of the variation in uncertainty associated with important business cycle variables such as industrial production $\left(R^{2}=0.64\right)$, industrial production in manufacturing $\left(R^{2}=0.65\right)$, capacity utilization $\left(R^{2}=0.59\right)$, employment in manufacturing $\left(R^{2}=0.57\right)$, and consumer prices $\left(R^{2}=0.75\right) .{ }^{11}$ To put these numbers in perspective, note that our data are monthly and

\footnotetext{
${ }^{11} \mathrm{~A}$ complete list of the results is provided in table A.1 in appendix A.
} 

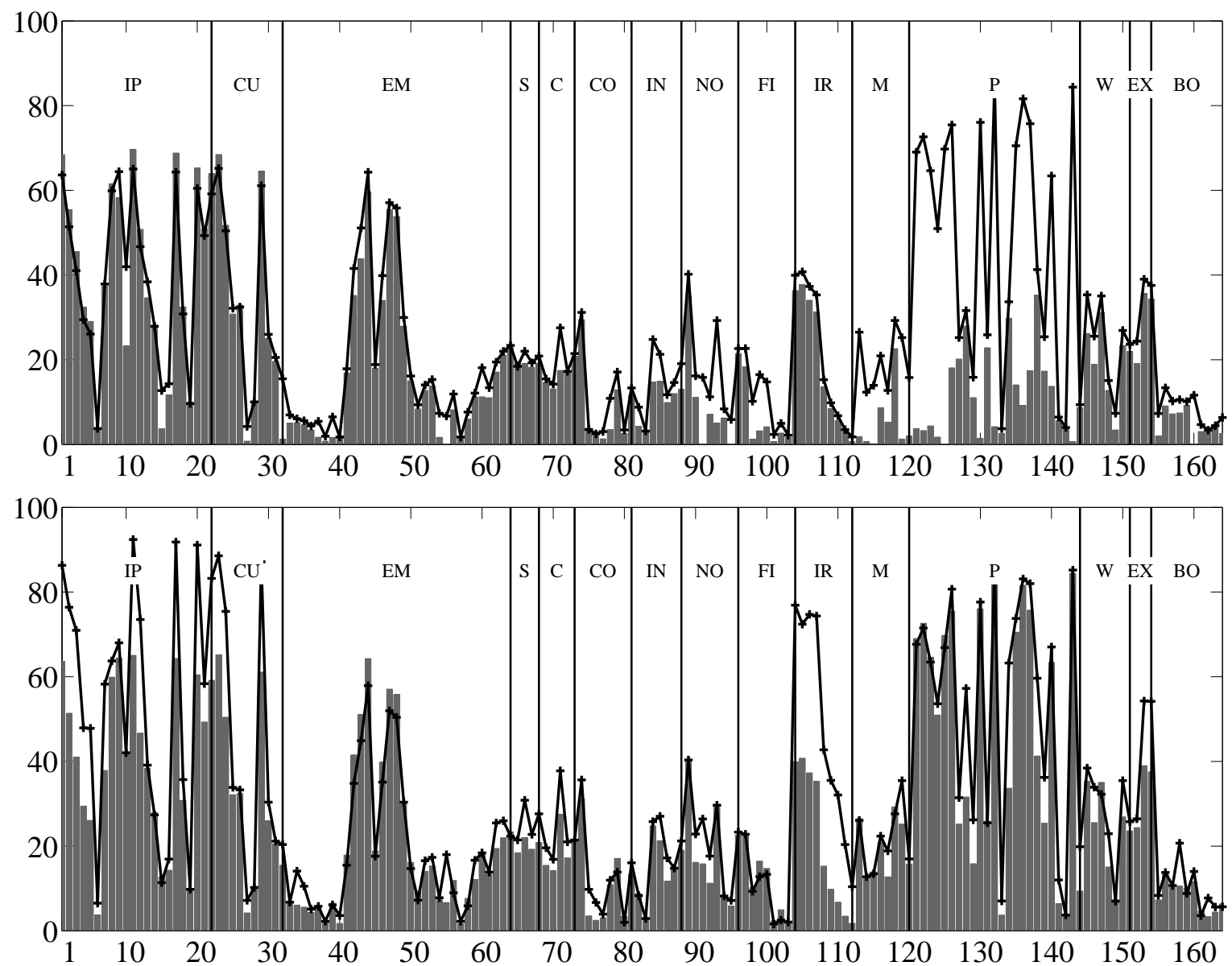

Note: The upper panel displays on the y-axis the respective proportion of the explained variance for $k=1$ (grey bars) and $k=2$ (crossed line). The lower panel documents the explained variance shares for $k=2$ (grey bars) and $k=3$ (crossed line). On the $x$-axis it depicts the individual uncertainty measures in the same order as in table A.1. They are grouped into the following categories: IP (1-21, industrial production), CU (22-31, capacity utilisation), EM (32-63, employment), S (64-67, sales), C (68-72, consumption), CO (73-80, housing and construction), IN (81-87, inventories), NO (88-95, new and unfilled orders), FI (96-104, financial variables), IR (105-113, interest rates), M (114-126, monetary variables), P (127-151, prices) , W (152-158, wages), EX (159-161, merchandise ex- and imports), BO (162-167, business outlook).

Figure 2: Explained variance proportions for different numbers of factors

the noise component thus accounts for roughly one third of the total variance. ${ }^{12}$

In appendix $C$ we also provide more formal tests for the number of common factors. Some caution is however warranted since the factors are themselves subject to estima-

\footnotetext{
${ }^{12}$ To arrive at this number we estimate the spectral density of each series and calculate the average contribution to the total variance of the frequencies smaller than 18 months. These frequencies are usually attributed to the noise component of a time series in the business cycle literature (see, for instance, the seminal work of Burns and Mitchell, 1946).
} 
tion error which introduces an additional layer to the dynamics of the data and makes the testing problem non standard. As a result standard tests might have problems in correctly determining the number of factors in our dataset. Overall, information criteria do not provide a clear-cut indication of the precise number of factors, yet they support the notion that this number hovers around two. In the following we will thus proceed the analysis using two common factors. ${ }^{13}$

\subsection{The different types of macroeconomic uncertainty}

To interpret the two fundamental shocks that govern the common dynamics of economic uncertainty we study the response of the individual uncertainty measures to each of these shocks. The factors have the moving average representation

$$
f_{t}=\left[I_{r}-\psi(L) L\right]^{-1} R u_{t} .
$$

It follows that the impulse response function of the common component $X_{t}=\lambda f_{t}$ is

$$
\begin{aligned}
x_{\mathrm{t}} & =\lambda\left[\mathrm{I}_{\mathrm{r}}-\psi(\mathrm{L}) \mathrm{L}\right]^{-1} \mathrm{R} \mathrm{u}_{\mathrm{t}}, \\
& =\mathrm{B}(\mathrm{L}) \mathrm{u}_{\mathrm{t}} .
\end{aligned}
$$

Given a rotation matrix $\mathrm{H}$ with $\mathrm{HH}^{\prime}=\mathrm{I}_{r}$, the common component can be rewritten as $X_{\mathrm{t}}=\mathrm{C}(\mathrm{L}) v_{\mathrm{t}}$, where $\mathrm{C}(\mathrm{L})=\mathrm{B}(\mathrm{L}) \mathrm{H}$ and $v_{\mathrm{t}}=\mathrm{H}^{\prime} u_{\mathrm{t}}$. However, there is an infinite number of rotation matrices $\mathrm{H}$ and the impulse response function is, in general, not identified. As proposed by Giannone et al. (2004) we solve the identification problem by selecting the rotation matrix $\mathrm{H}$ such that the target function

$$
g(H)=\frac{\sum_{i \in D} \sum_{l=0}^{\infty}\left(c_{i 1}^{l}\right)^{2}}{\sum_{i \in D} \sum_{l=0}^{\infty}\left(c_{i 1}^{l}\right)^{2}+\sum_{i \in D} \sum_{l=0}^{\infty}\left(c_{i 2}^{l}\right)^{2}}
$$

is maximized. The item $c_{i j}^{l}$ denotes the response of the individual uncertainty measure $i$ to innovation $j$ (for $j=1,2$ ) after $l$ periods. The selection vector $D$ identifies a subset of uncertainty measures which enters the target function. The denominator is the forecast error variance of the selected uncertainty measures which is explained by the two shocks jointly. The target function is thus based on the forecast error variance decomposition. In the baseline specification, we identify the first shock such that its explanatory

\footnotetext{
${ }^{13}$ We also provide a robustness exercise for our main results using a factor model with three common factors in appendix J.
} 
power for uncertainty surrounding all of the production variables is maximized, i.e. D identifies all uncertainty measures related to output (series 1 to 31). The identification strategy reflects the idea that the model should at least be able to capture fluctuations in production uncertainty. The second shock is left unrestricted.

To quantify the relative importance of each fundamental shock for individual uncertainty measures we perform a forecast error variance decomposition. Results for the 12-month horizon are reported in the columns labeled shock 1 and 2 in table A.1 in appendix A. Moreover, we use impulse response analysis to find out the sign (and the significance) of the response of individual uncertainty measures to a one standard deviation surprise increase in each of the two fundamental factors. Dynamic responses to an innovation in the first factor are displayed in the left column of figures 3 and 4, respectively. Responses to a similarly designed increase in the second factor are depicted in the corresponding right column. ${ }^{14}$

\footnotetext{
${ }^{14}$ Confidence intervals are obtained from a bootstrap procedure which is outlined in appendix D.
} 
Response to shock 1
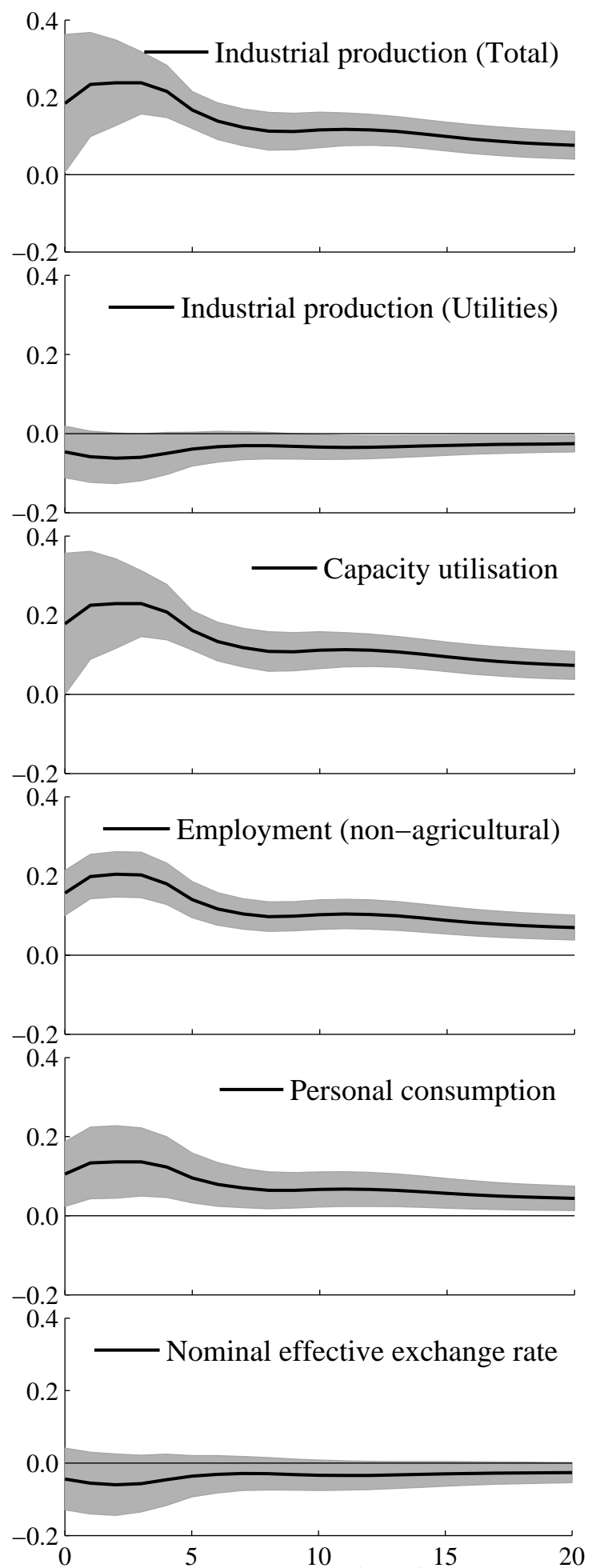

Response to shock 2
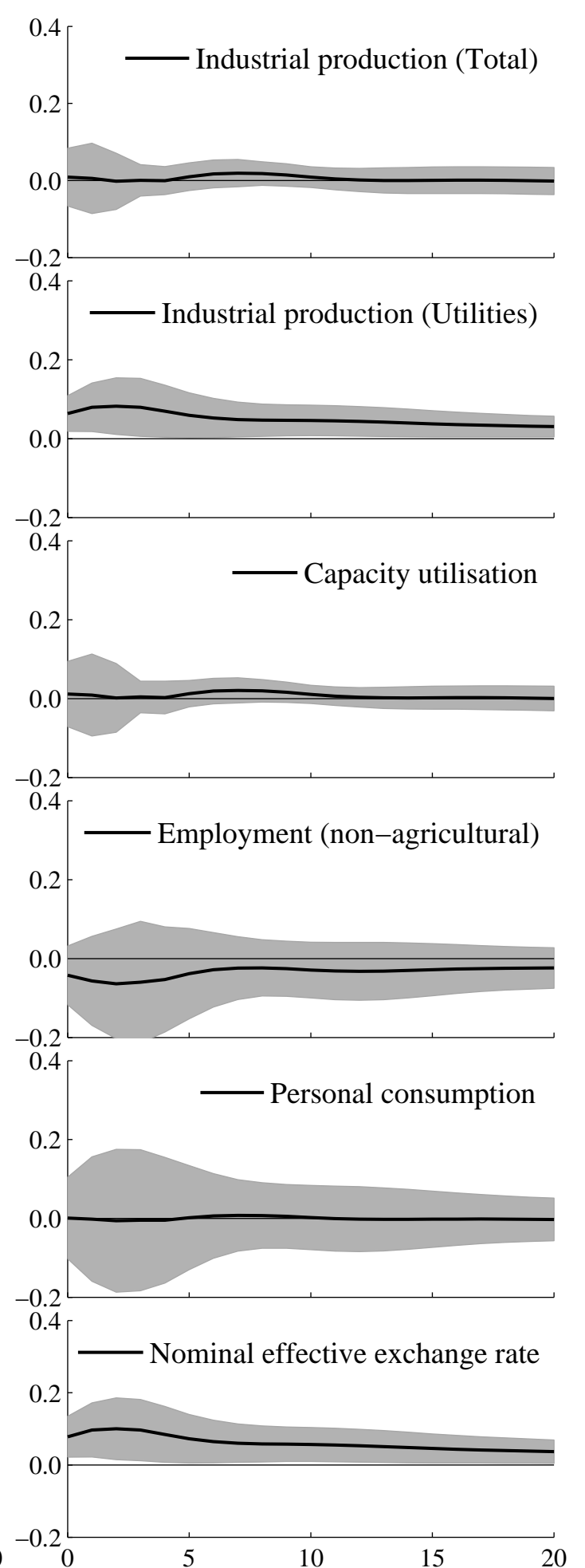

Note: Impulse responses to the first fundamental shock (left column) and to the second fundamental shock (right column) are indicated by the bold lines. Shaded areas display bootstrapped $90 \%$ confidence intervals.

Figure 3: Impulse responses of individual uncertainty measures (1) 
Response to shock 1
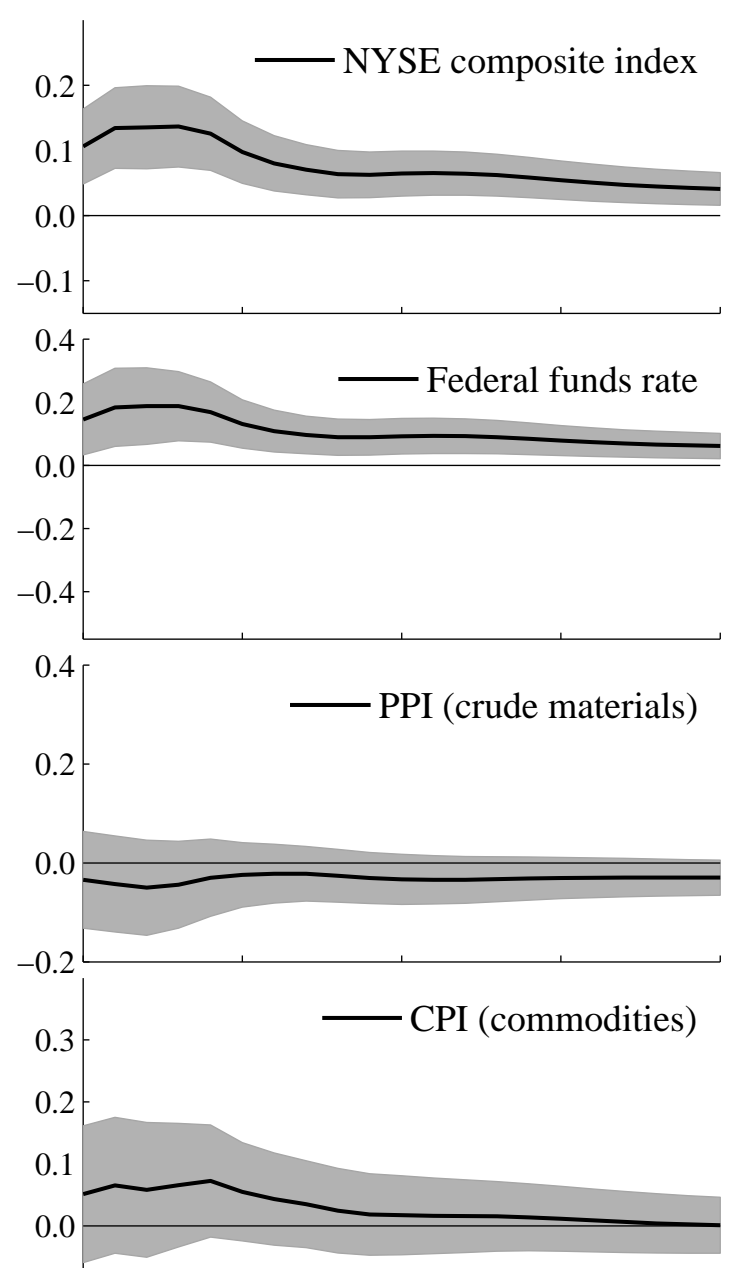

$-0$.
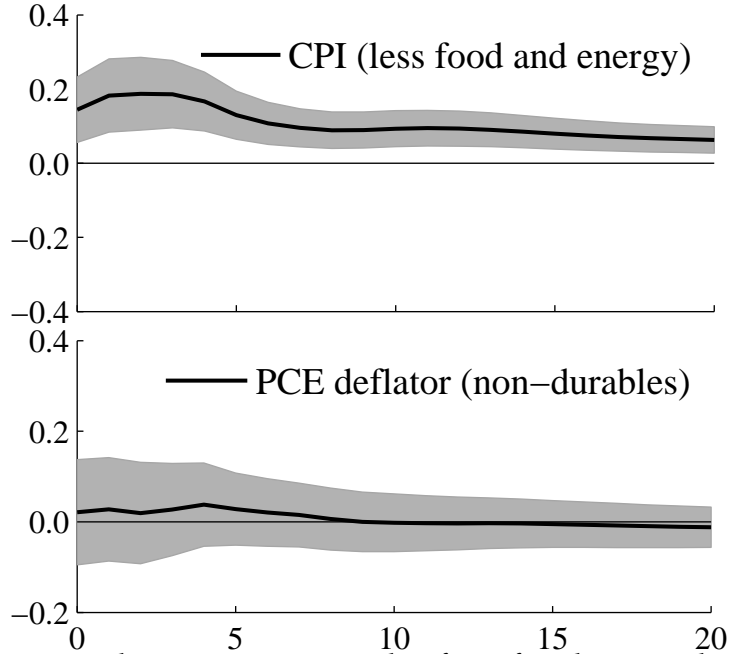

Response to shock 2
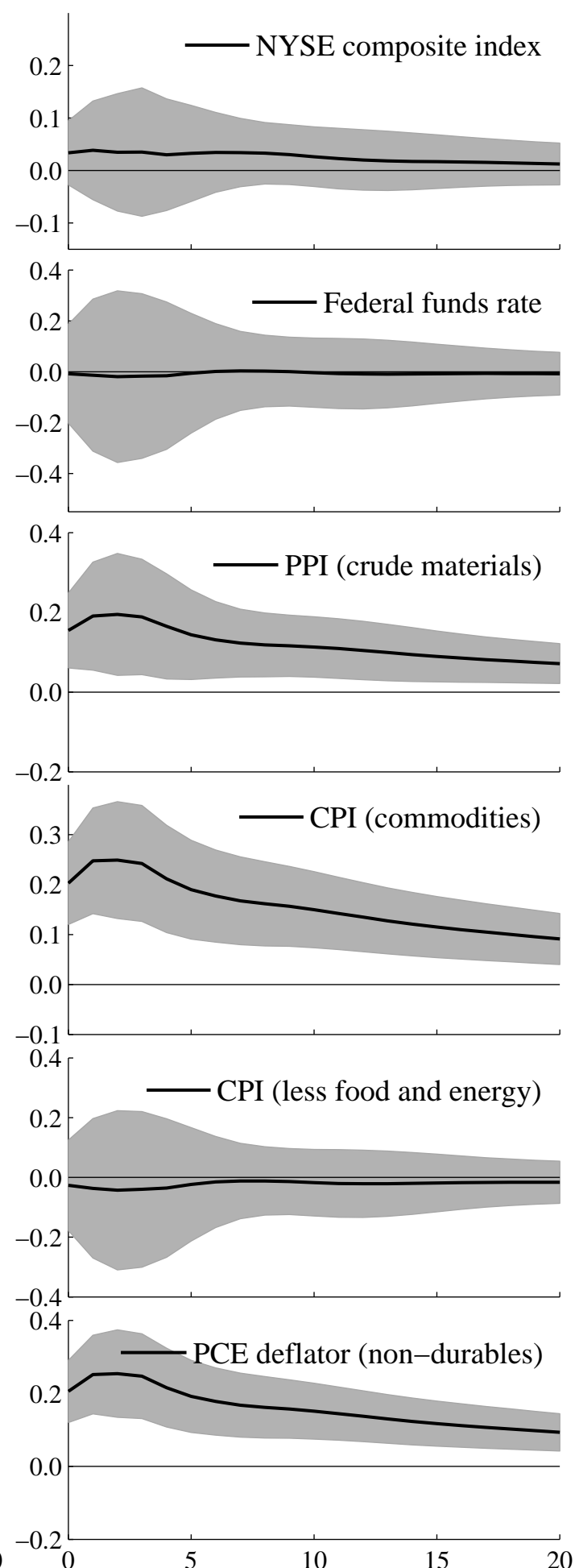

Note: Impulse responses to the first fundamental shock (left column) and to the second fundamental shock (right column) are indicated by the bold lines. Shaded areas display bootstrapped $90 \%$ confidence intervals.

Figure 4: Impulse responses of individual uncertainty measures (2) 
From the forecast error variance decomposition we infer that the first fundamental shock is important for fluctuations of uncertainty associated with aggregate production, capacity utilization, and aggregate employment. Moreover, uncertainty related to important business cycle indicators such as sales, consumption, inventories, and new orders as well as exports and imports is captured in most cases by shock 1 . The latter also explains a major fraction of fluctuations in stock market uncertainty. Moreover, this shock is an important driver of uncertainty related to the federal funds rate as well as for uncertainty surrounding assets which usually carry little risk such as the different treasuries. A mixed picture is obtained for the different inflation uncertainty measures. Shock 1 may explain uncertainty about core inflation, which is also closely linked to aggregate demand, while it does not contribute to uncertainty about other price variables related to (unprocessed) input goods such as commodities. The first shock also governs uncertainty about hourly earnings.

The impulse responses in figure 3 show that the first shock precedes a significant increase of uncertainty surrounding variables which bear a close relation to the business cycle, whereas it is not followed by an increase in uncertainty related to utility production and the nominal effective exchange rate. Moreover, figure 4 confirms that shock 1 is followed by a rise in uncertainty related to core inflation (CPI less food and energy), while there is no significant increase in inflation uncertainty measures for non-processed goods and non-durable consumption goods, which comprises mainly gasoline. ${ }^{15}$ Overall, our results suggest that shock 1 governs uncertainty surrounding variables which determine aggregate demand conditions in an economy and bear a close relation to the business cycle. We thus identify the first fundamental shock as 'business cycle uncertainty'.

In table A.1 we observe that the second fundamental shock is important for uncertainty surrounding the production of utilities. Shock 2 is also quantitatively important for uncertainty of all producer prices. Other price variables which are explained by this shock are those consumer prices which reflect energy price movements such as the CPI for transportation, for commodities, or the PCE deflator for non-durables. Moreover, shock 2 may explain a major fraction of uncertainty related to the exchange rate which itself is an important determinant of domestic energy and import prices.

The impulse responses in the right column of figure 3 confirm that there is no signif-

\footnotetext{
${ }^{15}$ There are also a number of individual uncertainty measures for which both fundamental shocks play a role. Notably, $73 \%$ (76\%) of the common variation in uncertainty surrounding CPI (PCE deflator) headline inflation is attributable to the second shock, and $27 \%(24 \%)$ are explained by the first shock. Furthermore, uncertainty related to total loans and securities is governed by both shocks.
} 
icant increase of uncertainty associated with most business cycle variables. The second shock precedes a rise in uncertainty associated with the production of utilities, and it is followed by higher exchange rate uncertainty. Moreover, figure 4 reveals that the second shock precedes an increase in uncertainty about prices of unprocessed goods such as oil and commodities. We thus identify this shock as 'oil and commodity price uncertainty'. ${ }^{16}$

In the following we compare the historical movements of shock 2 to the precautionary oil-market specific demand shock put forward by Kilian (2009). Such a shock may occur on the oil market when agents develop a precautionary demand for oil which serves as an insurance against a potential shortfall of oil supply. If shock 2 governs oil and commodity price uncertainty it should be related to Kilian's (2009) precautionary oil demand shock, which is identified using a VAR framework. ${ }^{17}$ Figure 5 shows that the peaks of both series are highly synchronized which suggests that they reflect the same oil-market specific events. However, both innovations do not operate in the same direction throughout. ${ }^{18}$ The economic interpretation of the oil-market specific demand shock and a shock in oil and commodity price uncertainty is thus rather different. While an increase in precautionary demand probably reflects the fear of rising oil prices, uncertainty may also increase when oil and commodity prices drop. Overall, these results provide further support for our interpretation of the second shock as oil and commodity price uncertainty.

\footnotetext{
${ }^{16}$ In appendix E we also perform a different rotation where we identify the second shock as driver of oil and commodity price uncertainty while the first shock is left unrestricted. The interpretation of the two fundamental shocks is robust to this change in the identification strategy.

${ }^{17}$ We have updated the shock series until 2011 using the material provided on Lutz Kilian's website: http://www-personal.umich.edu/ lkilian/.

${ }^{18}$ While, for instance, both series co-move during the Gulf Wars, a large drop in oil-specific demand is accompanied by a rise in oil and commodity price uncertainty during the global financial crisis. The sign of the oil-market specific demand shock is, for instance, negative during a recession when there are expectations about an oil production surplus. During such episodes oil and commodity price uncertainty typically increases.
} 


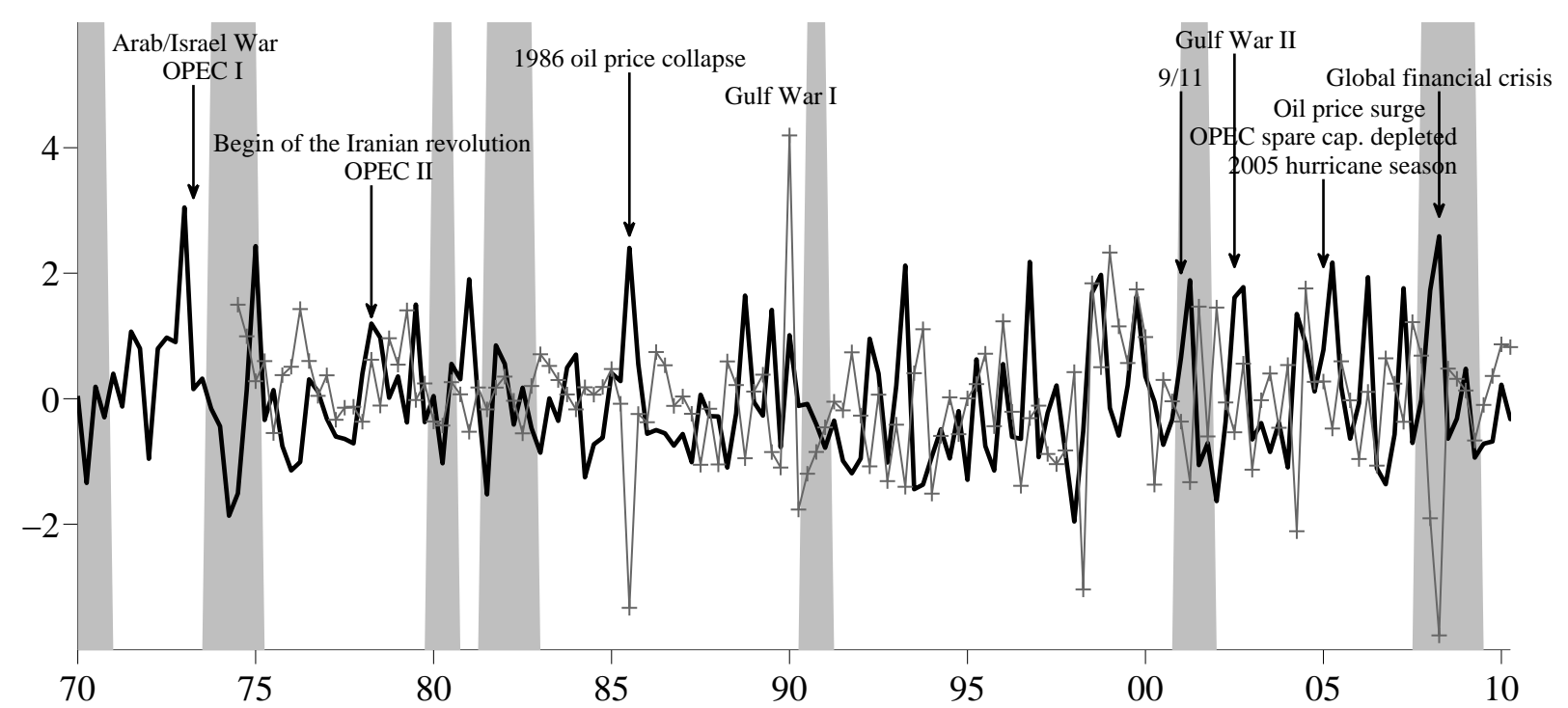

The thick black line represents innovations to oil and commodity price uncertainty, and the crossed thin red line depicts the oil-market specific demand shock of Kilian (2009). The correlation among both series is 0.23 and significant at the one percent level. Shaded areas represent NBER recession dates. To improve the readability, the figure presents quarterly averages, and the series are standardized.

Figure 5: Shock 2 and oil-market specific demand shock

\subsection{Indicators of macroeconomic uncertainty}

In the following we use the parametric structure of the dynamic factor model in (7) and (8) to derive two indicators of macroeconomic uncertainty. For this purpose we separately identify the $k=2$ common factors in $f_{t}=\left[f_{1, t} f_{2, t}\right]^{\prime}$. Since the factors are latent, we encounter a further identification problem which we solve using a matrix rotation procedure such that the proportion of variance explained by the first factor is maximized for uncertainty measures associated with output (series 1 to 31) (see also Kose, Otrok, and Prasad, 2012). This procedure is similar to the rotation approach used in section 4.2 , but focuses on uncertainty measures' unconditional variances instead of their forecast error variances. ${ }^{19}$ Note that while the fundamental shocks are orthogonal, this is not necessarily the case for the factors since they follow the VAR process in (8). However, when we calculate the variance decomposition for the VAR in the factors with respect to the elements in $u_{t}$, the first fundamental shock explains $98.4 \%$ of the forecast error variance of the first common factor $f_{1, t}$ twelve months ahead, while the second fundamental shock explains $94.4 \%$ of the variation in $f_{2, t}$. Our interpretation of the fundamental shocks thus carries over to the common factors, and $f_{1, t}$ is a measure of

\footnotetext{
${ }^{19}$ In appendix $\mathrm{F}$ we present the details of the rotation strategy that we use to separately identify the two factors.
} 
business cycle uncertainty whereas $f_{2, t}$ provides a measure of oil and commodity price uncertainty.

\section{Business cycle uncertainty}
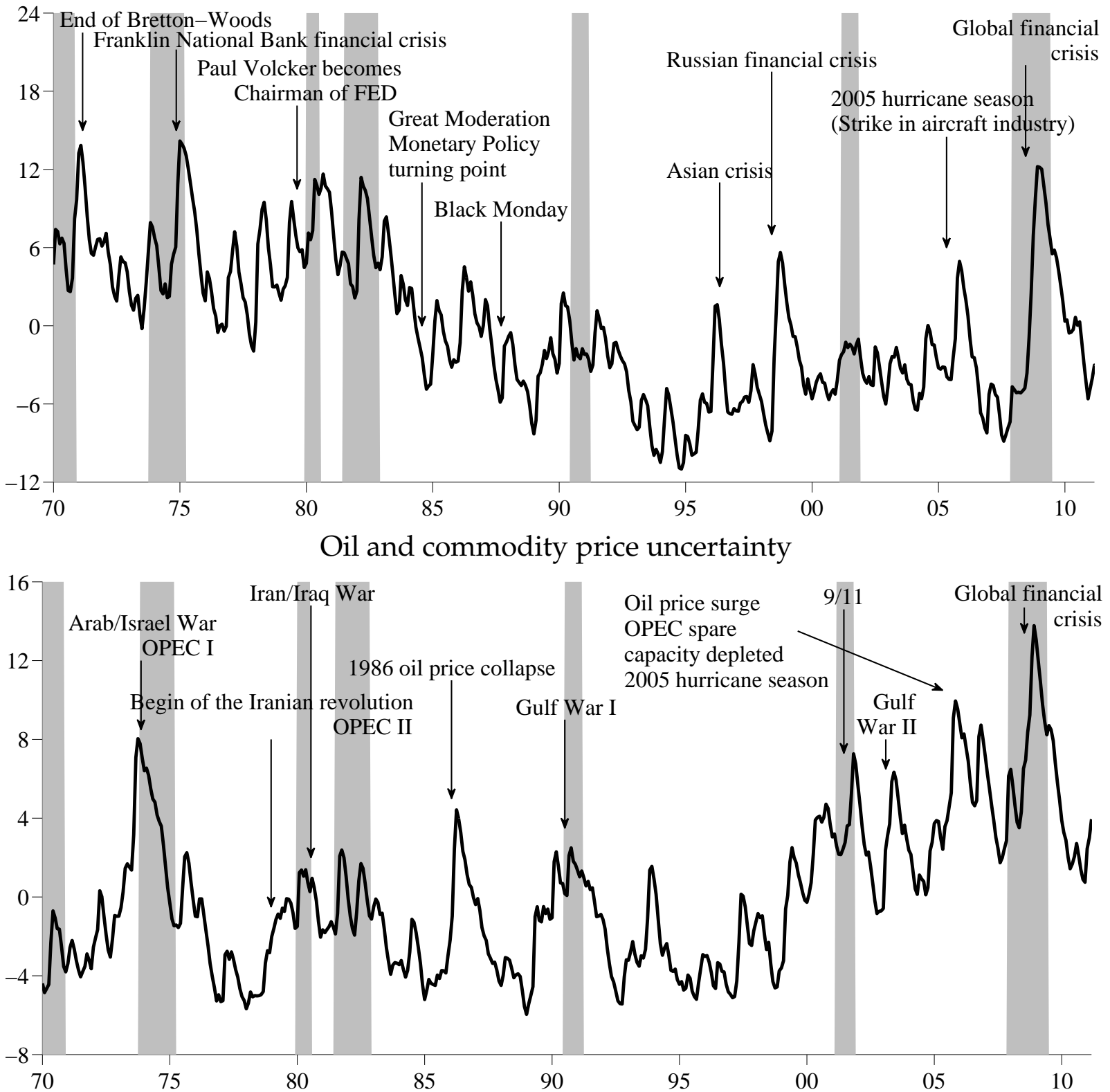

The upper panel depicts business cycle uncertainty $\left(f_{1, t}\right)$ and the lower panel depicts oil and commodity price uncertainty $\left(f_{2, t}\right)$. NBER recession dates are indicated by the shaded areas.

Figure 6: Indicators of macroeconomic uncertainty

Time paths of both indicators of macroeconomic uncertainty are linked to major 
events that are commonly associated with economic turmoil. ${ }^{20}$ In figure 6 the upper panel displays our indicator of business cycle uncertainty along with important business cycle events. NBER dated recessions are indicated by shaded areas. It becomes apparent that business cycle uncertainty is countercyclical since it rises during recessions. The indicator of business cycle uncertainty first soars when the Bretton-Woods system collapsed in 1973. The next extraordinary peak is related to the bankruptcy of the Franklin National Bank in 1974 which led to a banking crisis and a period of increased macroeconomic turmoil. Moreover, the indicator peaks in 1979 when Paul Volcker became chairman of the FED and changed the conduct of monetary policy. In the period extending from the mid-1980s, business cycle uncertainty retraces the decline of macroeconomic volatility known as the 'Great Moderation'. Business cycle uncertainty increases only moderately around the Black Monday in 1987, while a more pronounced increase is observed during the Asian crisis, the Russian financial crisis, during 2005 hurricane season ('Hurricane Katrina'), and after the bankruptcy of Lehman Brothers in 2008 which preceded the global financial crisis.

Oil and commodity price uncertainty is displayed in the lower panel of figure 6 along with oil-market specific events and NBER dated recessions. Like business cycle uncertainty, oil and commodity price uncertainty rises during recessions. Peaks occur in 1973 during the Arabian/Israel War, the Iranian Revolution 1978/79, and the Iran/Iraq War in 1980, as well as in 1986 when the oil price dropped heavily, and during the first Gulf War in 1990/91. Beginning in the mid-1990s oil and commodity price uncertainty is characterized by an upward trending pattern which coincides with a time when the OPEC repeatedly adjusted its quotas. The indicator rises sharply around 9/11 when changes in the oil production quota were no longer sufficient to stabilize the oil price. Afterwards, it increases moderately during the second Gulf War and peaks in the mid2000s reflecting the decrease in oil spare capacity in the aftermath of the second Gulf War. At the beginning of the global financial crisis the oil price first increased until its sudden decline accompanied by a hike in oil and commodity price uncertainty.

Several alternative measures have been proposed to investigate the dynamics of uncertainty in the macroeconomy and its relation to economic activity. A number of studies use the option-based CBOE implied volatility index (VXO) to measure uncertainty perceived on financial markets (see, for instance, Bloom, 2009; Basu and Bundick, 2012).

\footnotetext{
${ }^{20}$ As discussed in section 3.1, we calculate uncertainty indicators based on real time forecast errors in appendix $\mathrm{G}$ as a robustness check. The indicators of macroeconomic uncertainty are almost unaffected by using either in-sample or out-of-sample forecast errors.
} 
Figure 7 compares the VXO and business cycle uncertainty. ${ }^{21}$ Both series increase swiftly around, for instance, the Franklin National Bank crisis, during the Russian financial crisis, and during the recent global financial crisis. Yet, the tightness of the relation among both measures varies over time. Particularly, VXO peaks around the Black Monday and the stock market crash of 2002 while there is virtually no reaction of business cycle uncertainty. The comparison of VXO to the indicator of oil and commodity price uncertainty is provided in the lower panel of figure 7 . We also observe that these two measures are synchronized during certain episodes.

The results of a regression of VXO on contemporaneous values of business cycle uncertainty and oil and commodity price uncertainty are reported in the first row of table 1. Both uncertainty factors are significant which suggests that VXO reflects, both, business cycle uncertainty and oil and commodity price uncertainty.

\begin{tabular}{r|lll}
\hline $\mathrm{Z}$ & $\alpha_{1}$ & $\alpha_{2}$ & $\mathrm{R}^{2}$ \\
\hline$V X O$ & $0.17^{* *}$ & $0.32^{* * *}$ & 0.14 \\
SPREAD & $0.44^{* * *}$ & $0.32^{* * *}$ & 0.32 \\
$J L N$ & $0.59^{* * *}$ & $0.48^{* * *}$ & 0.62 \\
$E P U$ & $0.48^{* * *}$ & 0.01 & 0.23 \\
\hline
\end{tabular}

Note: For each alternative measure we run the following regression: $Z_{t}=\alpha_{1} f_{1, t}+\alpha_{2} f_{2, t}+d_{O c t 87}+\eta_{t}$, where $Z_{\mathrm{t}} \in\{$ VXO, SPREAD, JLN, EPU $\}$. VXO: CBOE stock market volatility index (Bloom, 2009), SPREAD: 30year Baa corporate bond spread, JLN: Measure used in Jurado et al. (2014), EPU: Index of economic policy uncertainty (Baker et al., 2013). All series are quarterly averages and standardized. Significance at the $10 \%, 5 \%, 1 \%$ level is denoted by $*, * *, * * *$. The regressions contain a dummy for the Black Monday $\mathrm{d}_{\text {Oct } 87}$.

Table 1: Regression on the uncertainty indicators

Similarly, credit spreads (SPREAD) may be used to measure the perception of risk of financial investors (Gilchrist, Yankov, and Zakrajšek, 2009; Gilchrist and Zakrajšek, 2012; Bachmann et al., 2013). ${ }^{22}$ Table 1 documents that the regression result is similar to that of the VXO. Although financial market uncertainty appears to be related to macroeconomic uncertainty, they differ in a non-negligible way. Turmoil and mass panic on financial markets (e.g. during the 'Black Monday') do not necessarily root in bad economic fundamentals. Another explanation for the differences may be that the VXO is to a large extent influenced by time-varying risk aversion of financial investors which is unrelated to economic uncertainty (Bekaert et al., 2013). Using financial market uncertainty as a measure for macroeconomic uncertainty may thus be misleading (Jurado

\footnotetext{
${ }^{21}$ To obtain a long history of implied stock market volatility we use Bloom's (2009) measure which dates back to 1962 .

${ }^{22}$ The time profiles of alternative uncertainty measures along with the indicators of macroeconomic uncertainty are provided in appendix $\mathrm{H}$.
} 

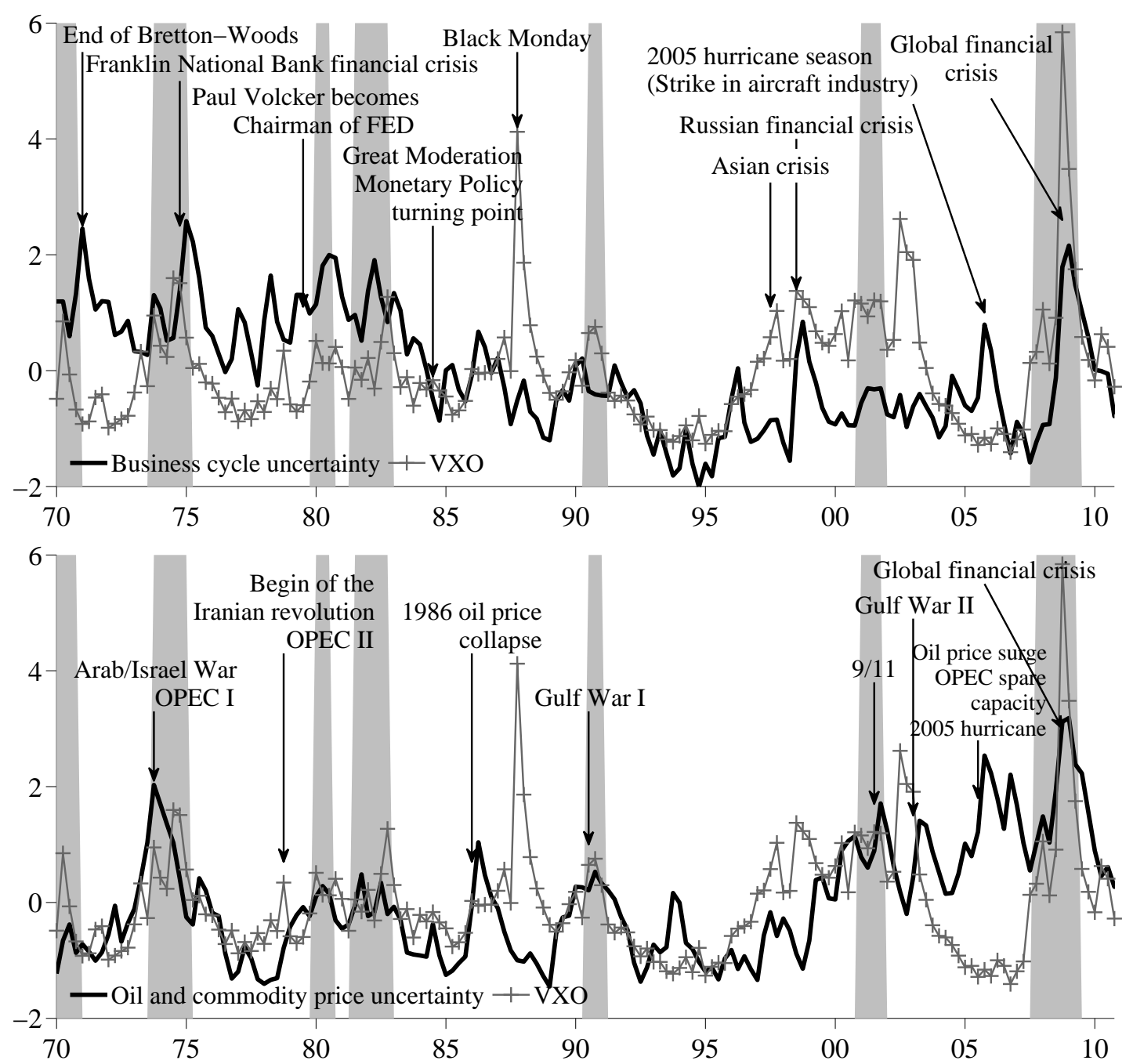

Note: The upper panel depicts business cycle uncertainty and the lower panel oil and commodity price uncertainty. The crossed (red) line represents stock market volatility (VXO). To facilitate the interpretation of the graph, we calculate quarterly averages of the monthly series and standardize all series. NBER recession dates are indicated by the shaded areas.

Figure 7: Indicators of macroeconomic uncertainty and VXO

et al., 2014, reach a similar conclusion).

The measure of Jurado et al. (2014) is conceptually close to ours since it defines macroeconomic uncertainty as the common factor with largest explanatory power behind a large number of individual uncertainty measures. We obtain a positive and significant regression coefficient for both measures of macroeconomic uncertainty. Since Jurado et al. (2014) focus on one factor they can not distinguish between different types of macroeconomic uncertainty. Indeed, it appears that our identification strategy allows us to discriminate two types of uncertainty which are otherwise combined in the factor 
with the largest explanatory power.

Baker et al. (2013) propose a measure of economic policy uncertainty (EPU) which is derived from newspaper references to policy, tax rate and fiscal budget uncertainty. EPU, by design, reflects a specific type of uncertainty relating exclusively to future policy decisions. The regression results in table 1 reveal a significantly positive contemporaneous relation to business cycle uncertainty but not to oil and commodity price uncertainty. Given that EPU seems to reflect business cycle uncertainty only, the comparison confirms our interpretation of the uncertainty factors. ${ }^{23}$

\subsection{Macroeconomic uncertainty and real activity}

We now turn our attention to the dynamic relation between macroeconomic uncertainty and economic activity. Economic activity and macroeconomic uncertainty may however be highly endogenous (see, for instance, Bachmann and Moscarini, 2012). To meet this concern we estimate a number of bivariate VARs which is a parsimonious way to model the joint dynamics of both variables while controlling for the interrelations among them. Each VAR consists of one uncertainty factor $f_{j, t}$, for $j=1,2$, and one additional variable representing economic activity. To study the response of real activity we consider industrial production (IP), capacity utilization (CU), and average hours (Hours). ${ }^{24}$ These variables enter in log-levels. We include a linear trend and set the lag length for each VAR to 12 which is sufficient to control for the dynamic history of the variables. The VAR innovations are orthogonalized by means of a Cholesky decomposition where the respective uncertainty factor is ordered last. This ordering implies that uncertainty reacts instantaneously while macroeconomic quantities - which are comparatively slowmoving - are affected after one month. Moreover, it ensures that we control for firstmoment shocks when we analyze the result of a surprise increase in macroeconomic uncertainty. The size of the shock to uncertainty is chosen to obtain an initial increase of macroeconomic uncertainty equal to its observed average monthly increase during the global financial crisis in the second half of 2008. Such a calibration entails that the size of the shock to business cycle uncertainty is 2.8 standard deviations, and the shock to

\footnotetext{
${ }^{23}$ As a robustness exercise we also calculate the dynamic response of VXO, SPREAD, JLN, and EPU to the two fundamental shocks $\mathfrak{u}_{1}$ and $\mathfrak{u}_{2}$ in appendix I. Since the dynamic relations are very similar to the contemporaneous ones this exercise further strengthens our results.

${ }^{24}$ As in Bloom (2009), Bachmann et al. (2013), and Jurado et al. (2014) we focus on the manufacturing sector.
} 
oil and commodity price uncertainty has a size of 1.6 standard deviations. ${ }^{25}$

The upper panel of figure 8 collects the impulse responses for a shock to business cycle uncertainty. It appears that the average monthly increase in business cycle uncertainty during the financial crisis leads to a drop in production by $0.6 \%$ after six months which is followed by a rebound. A similar path is obtained for capacity utilization and hours worked which decline by $0.9 \%$ and $0.2 \%$, respectively. Our results thus confirm the findings documented in previous studies which argue that macroeconomic uncertainty foreshadows economic downturns (see, for instance, Bloom, 2009; Bloom et al., 2012; Bachmann et al., 2013).

The lower panel of figure 8 displays the response to a surprise innovation in oil and commodity price uncertainty as observed during the global financial crisis. In this case, we observe a long-lasting decline of IP which is much more pronounced than for business cycle uncertainty, IP drops by $1.5 \%$ after about two years. Similarly, capacity utilization drops by $1.3 \%$, and also the decline of hours worked is more pronounced $(-0.4 \%)$. Since we calibrate the shock to the average increase during the global financial crisis, the size of the shock to oil and commodity price uncertainty is smaller than the shocks to business cycle uncertainty. Nevertheless, the former precedes a stronger decline in real activity. ${ }^{26}$

We conduct several robustness checks documented in appendix $\mathrm{K}$. We calculate the impulse response functions of IP for VAR systems where we choose the lag length for the bivariate VARs by BIC. We also estimate a version without trend. Moreover, we checked whether the ordering has an impact on the impulse responses. Following the previous literature we also estimate larger VARs consisting of eight variables (Bloom, 2009; Bachmann et al., 2013; Jurado et al., 2014). The ordering of the variables is: IP, employment, Hours, CPI, hourly wages, federal funds rate, macroeconomic uncertainty, S\&P 500 Stock prices, and all variables except for the interest rate and macroeconomic uncertainty enter in log-levels. Overall, our results are robust to these changes.

We calculate the shares of the forecast error variance attributable to each type of macroeconomic uncertainty in table 2 . Increases in business cycle uncertainty explain at most $1.2 \%$ of the fluctuations of IP, for CU the largest share is $10.7 \%$, and for hours worked it is $4.6 \%$. By contrast, up to $21.5 \%$ of the fluctuations of IP are attributable to a

\footnotetext{
${ }^{25}$ Commonly, the uncertainty shock in VARs is calibrated for rare events like the global financial crisis, Bloom (2009) and Jurado et al. (2014) consider a four standard deviation shock.

${ }^{26}$ In appendix J we demonstrate that this result also holds when we allow for $k=3$ factors when estimating the factor model in (7) and (8).
} 

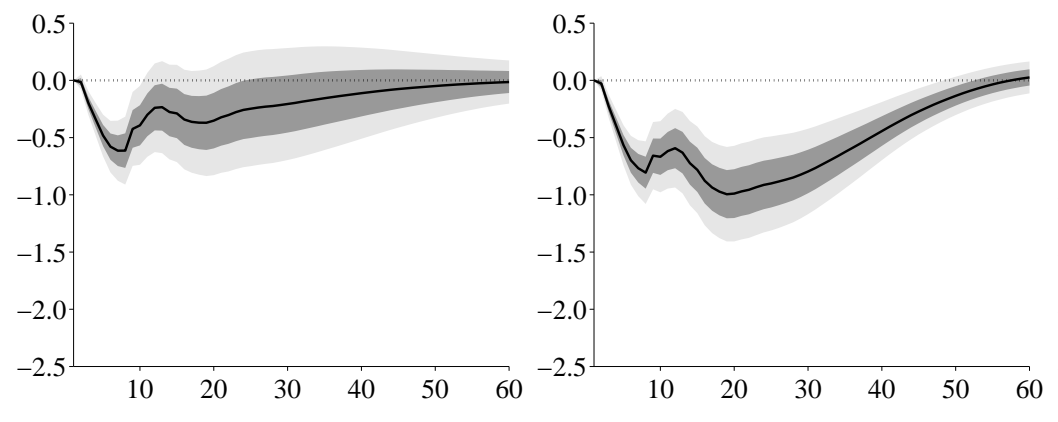

IP to $f_{2}$

$\mathrm{CU}$ to $f_{2}$

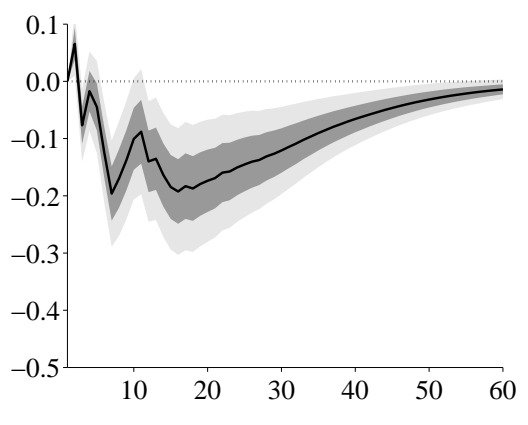

Hours to $f_{2}$
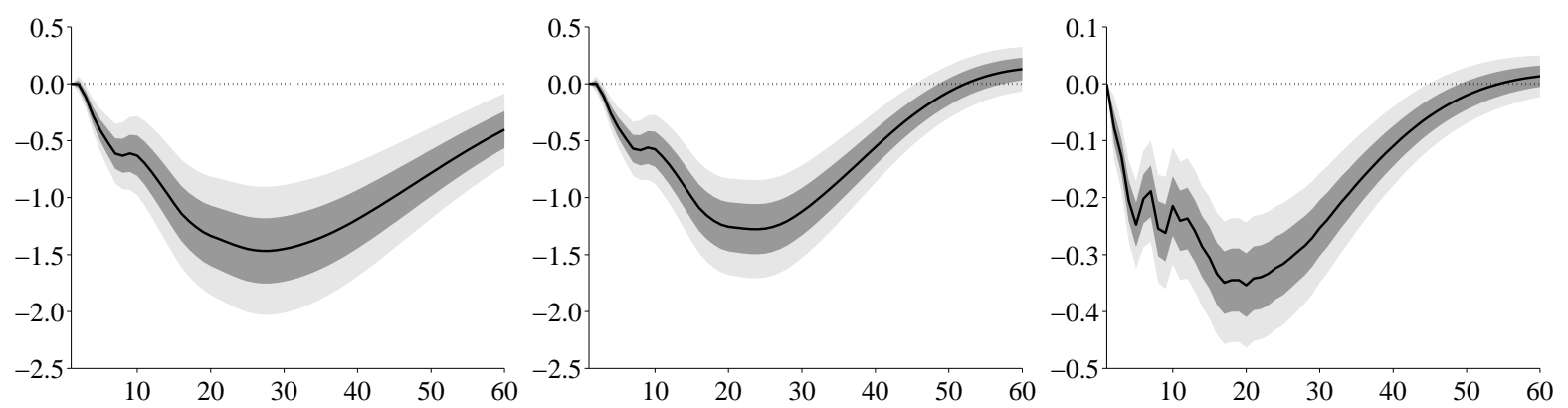

Note: The upper panel depicts the response of industrial production (IP), capacity utilization (CU), and hours worked (Hours) to a surprise innovation in business cycle uncertainty. The lower panel depicts the response of the same variables to a shock to oil and commodity price uncertainty. The shock size is chosen to obtain an initial increase of macroeconomic uncertainty equal to its observed average monthly increase in the second half of 2008. Confidence intervals are derived from the bias adjusted bootstrap procedure (Kilian, 1998). Dark shaded areas indicate the \pm one standard deviation confidence interval, light shaded areas indicate \pm two standard deviations.

Figure 8: Impulse response functions for a surprise increase in macroeconomic uncertainty

sudden increase in oil and commodity price uncertainty, while for $\mathrm{CU}$ the ratio is $25.6 \%$ and for hours worked it is $27.2 \%$. In appendix $\mathrm{L}$ we demonstrate that this result also holds in a VAR containing both types of macroeconomic uncertainty at the same time, i.e. when we control for innovations in business cycle uncertainty. Moreover, appendix M documents that using a larger VAR as in Bloom (2009) does not change this result. 


\begin{tabular}{rrrrrrrrr}
\hline & \multicolumn{3}{c}{$\begin{array}{c}\text { Business cycle } \\
\text { uncertainty }\end{array}$} & & \multicolumn{3}{c}{$\begin{array}{c}\text { Oil and commodity } \\
\text { price uncertainty }\end{array}$} \\
\cline { 2 - 4 } \cline { 8 - 9 } Horizon & IP & CU & Hours & & IP & CU & Hours \\
\hline 12 & 1.20 & 3.28 & 1.22 & & 3.22 & 3.82 & 7.22 \\
24 & 0.90 & 7.13 & 3.33 & & 10.18 & 15.93 & 20.29 \\
36 & 0.84 & 10.33 & 4.35 & & 16.70 & 24.75 & 26.49 \\
60 & 0.83 & 10.71 & 4.65 & & 21.54 & 25.64 & 27.23 \\
\hline
\end{tabular}

Note: This table presents the share of the forecast error variance (\%) due to business cycle uncertainty (left panel) and oil and commodity price uncertainty (right panel). The shares are obtained from bivariate VARs with 12 lags consisting of one type of macroeconomic uncertainty and one measure of economic activity. Rows contain results for different forecast horizons.

Table 2: Forecast error variance explained by macroeconomic uncertainty

In sum, our results are in line with the notion that uncertainty foreshadows an economic downturn. Yet, our findings suggest that unforeseen increases in the uncertainty factor which we identify as oil and commodity price uncertainty seems to be more important for real activity than business cycle uncertainty.

\section{Conclusions}

Economic uncertainty has recently been identified as a potential cause of business cycle fluctuations. However, the movements of almost all variables of an economy are subject to time varying uncertainty. As a consequence, numerous individual uncertainty measures may be obtained which entails a monitoring problem for the policy maker and the researcher alike. In the present paper, we unravel the fundamental factors governing the uncertainty about macroeconomic outcomes by means of a dynamic factor model. We interpret the common dynamics underlying individual uncertainty measures as macroeconomic uncertainty.

First, we document that only a small number of fundamental factors account for the movements of macroeconomic uncertainty. Our results suggest that two shocks are responsible for the common dynamics of the individual uncertainty measures, i.e. the dimension of macroeconomic uncertainty is two. Second, we demonstrate that the first factor is related to uncertainty surrounding variables which are closely linked to common business cycle variables and is thus interpreted as 'business cycle uncertainty' while the second factor reflects 'oil and commodity price uncertainty'. Third, we analyze how these types of macroeconomic uncertainty relate to alternative measures applied in the literature. Both types of macroeconomic uncertainty come along with an 
increase in financial market uncertainty as measured by the VXO and the spread for Baa rated corporate bonds. However, measures such as the VXO or SPREAD should be interpreted carefully since they may indicate uncertainty which is unrelated to macroeconomic fundamentals. Fourth, economic policy uncertainty as proposed in Baker et al. (2013) is closely related to business cycle uncertainty but not to oil and commodity price uncertainty.

In line with the previous literature we demonstrate that uncertainty is countercyclical. Yet, both types of macroeconomic uncertainty have different quantitative implications for real activity. Business cycle uncertainty precedes a short-lived and not very pronounced decline in output. In fact, our results suggest that the large swings in business cycle uncertainty are more likely a by-product of recessions than a cause (see Bachmann and Moscarini, 2012, for a theoretical argument). By contrast, oil and commodity price uncertainty appears to foreshadow a large and persistent drop in real activity. Overall, time-varying oil and commodity price uncertainty appears to be more important for fluctuations of real activity than business cycle uncertainty. 


\section{References}

Ahn, S. C. and A. R. Horenstein (2013). Eigenvalue ratio test for the number of factors. Econometrica 81(3), $1203-1227$.

Alexopoulos, M. and J. Cohen (2009). Uncertain times, uncertain measures. University of Toronto Working Paper 352.

Andersen, T. G., T. Bollerslev, P. F. Christoffersen, and F. X. Diebold (2006). Volatility and correlation forecasting, Volume 1 of Handbook of Economic Forecasting, Chapter 15, pp. 777-878. Elsevier.

Arellano, C., Y. Bai, and P. J. Kehoe (2012). Financial markets and fluctuations in uncertainty. Federal Reserve Bank of Minneapolis, March 2012, Staff Report.

Bachmann, R. and C. Bayer (2013). 'Wait-and-see' business cycles? Journal of Monetary Economics 60(6), 704-719.

Bachmann, R., S. Elstner, and E. R. Sims (2013). Uncertainty and economic activity: Evidence from business survey data. American Economic Journal: Macroeconomics 5(2), 217-49.

Bachmann, R. and G. Moscarini (2012). Business cycles and endogenous uncertainty. Yale University, Manuscript.

Bai, J. and S. Ng (2002). Determining the number of factors in approximate factor models. Econometrica $70(1)$, pp. 191-221.

Bai, J. and S. Ng (2007). Determining the number of primitive shocks in factor models. Journal of Business and Economic Statistics 25(1), 52-60.

Bai, J. and S. Ng (2008). Large dimensional factor analysis. Foundations and Trends in Econometrics 3(2), 89-163.

Baillie, R. T., C.-F. Chung, and M. A. Tieslau (1996). Analysing inflation by the Fractionally Integrated ARFIMA-GARCH model. Journal of Applied Econometrics 11(1), 23-40.

Baker, S. R., N. Bloom, and S. J. Davis (2013). Measuring economic policy uncertainty. Stanford University, Manuscript.

Ball, L. (1992). Why does high inflation raise inflation uncertainty? Journal of Monetary Economics 29, 371-388.

Bańbura, M., D. Giannone, and L. Reichlin (2011). Nowcasting. In M. P. Clements and D. F. Hendry (Eds.), Oxford Handbook on Economic Forecasting. Oxford University Press, Oxford.

Bańbura, M. and M. Modugno (2012). Maximum likelihood estimation of factor models on datasets with arbitrary pattern of missing data. Journal of Applied Econometrics, 1-27. 
Basu, S. and B. Bundick (2012). Uncertainty shocks in a model of effective demand. NBER Working Paper 18420.

Bekaert, G., M. Hoerova, and M. Lo Duca (2013). Risk, uncertainty and monetary policy. Journal of Monetary Economics 60(7), 771-788.

Bloom, N. (2009). The impact of uncertainty shocks. Econometrica 77(3), 623-686.

Bloom, N., M. Floetotto, N. Jaimovich, I. Saporta-Eksten, and S. J. Terry (2012). Really uncertain business cycles. NBER Working Paper 18245.

Born, B. and J. Pfeifer (2013). Policy risk and the business cycle. CESifo Working Paper Series 4336, CESifo Group Munich.

Burns, A. F. and W. C. Mitchell (1946). Measuring business cycles. NBER.

Doz, C., D. Giannone, and L. Reichlin (2012). A quasi-maximum likelihood approach for large, approximate dynamic factor models. The Review of Economics and Statistics 94(4), 1014-1024.

Elder, J. and A. Serletis (2010). Oil price uncertainty. Journal of Money, Credit and Banking 42(6), 1137-1159.

Fernández-Villaverde, J., P. Guerrón-Quintana, K. Kuester, and J. Rubio-Ramírez (2013). Fiscal volatility shocks and economic activity. University of Pennsylvania, manuscript.

Fernández-Villaverde, J. and J. F. Rubio-Ramírez (2010). Macroeconomics and volatlility: Data, models, and estimation. NBER Working Paper 16618.

Fernández-Villaverde, J., P. Guerrón-Quintana, and J. F. Rubio-Ramírez (2010). Fortune or virtue: Timevariant volatilities versus parameter drifting in U.S. data. NBER Working Paper 15928.

Fernández-Villaverde, J., P. Guerrón-Quintana, J. F. Rubio-Ramírez, and M. Uribe (2011). Risk matters: The real effects of volatility shocks. American Economic Review 101(6), 2530-61.

Forni, M., D. Giannone, M. Lippi, and L. Reichlin (2007). Opening the black box - structural factor models with large gross-sections. European Central Bank, Working Paper 702.

Forni, M. and L. Reichlin (1998). Let's get real: A factor analytical approach to disaggregated business cycle dynamics. Review of Economic Studies 65(3), 453-73.

Friedman, M. (1977). Nobel lecture: Inflation and unemployment. The Journal of Political Economy 85(3), 451-472.

Giannone, D., L. Reichlin, and L. Sala (2002). Tracking Greenspan: Systematic and unsystematic monetary policy revisited. CEPR Discussion Paper 3550.

Giannone, D., L. Reichlin, and L. Sala (2004). Monetary policy in real time. NBER Macroeconomics Annual 19, 161-224. 
Gilchrist, S., J. W. Sim, and E. Zakrajšek (2014). Uncertainty, financial frictions, and investment dynamics. NBER Working Papers 20038, National Bureau of Economic Research, Inc.

Gilchrist, S., V. Yankov, and E. Zakrajšek (2009). Credit market shocks and economic fluctuations: Evidence from corporate bond and stock markets. Journal of Monetary Economics 56(4), 471-492.

Gilchrist, S. and E. Zakrajšek (2012). Credit spreads and business cycle fluctuations. American Economic Review 102(4), 1692-1720.

Giordani, P. and P. Söderlind (2003). Inflation forecast uncertainty. European Economic Review 47, 10371059 .

Gonçalves, S. and L. Kilian (2004). Bootstrapping autoregressions with conditional heteroskedasticity of unknown form. Journal of Econometrics 123, 89-120.

Grier, K. and M. Perry (2000). The effects of real and nominal uncertainty on inflation and output growth: Some GARCH-M evidence. Journal of Applied Econometrics 15, 45-58.

Grier, K. B. and M. J. Perry (1998). On inflation and inflation uncertainty in the G7 countries. Journal of International Money and Finance 17(4), 671-689.

Grimme, C., S. R. Henzel, and E. Wieland (2014). Inflation uncertainty revisited: A proposal for robust measurement. Empirical Economics. forthcoming.

Hallin, M. and R. Liška (2007). Determining the number of factors in the general dynamic factor model. Journal of the American Statistical Association 102, 603-617.

Jurado, K., S. C. Ludvigson, and S. Ng (2014). Measuring uncertainty. New York University, manuscript.

Kilian, L. (1998). Small-sample confidence intervals for impulse response functions. The Review of Economics and Statistics 80, 218-230.

Kilian, L. (2009). Not all oil price shocks are alike: Disentangeling demand and supply shocks in the Crude Oil market. American Economic Review 99(3), 1053-1069.

Knotek II, E. S. and S. Khan (2011). How do households respond to uncertainty shocks? Economic Review (Q II). Federal Reserve Bank of Kansas City.

Kose, M. A., C. Otrok, and E. Prasad (2012). Global business cycles: Convergence or decoupling? International Economic Review 53(2), 511-538.

Kose, M. A., C. Otrok, and C. H. Whiteman (2003). International business cycles: World, region, and country-specific factors. American Economic Review 93(4), 1216-1239.

Lahiri, K. and X. Sheng (2010). Measuring forecast uncertainty by disagreement: The missing link. Journal of Applied Econometrics 25(4), 514-538.

Liesenfeld, R. and J.-F. Richard (2003). Univariate and multivariate stochastic volatility models: Estimation and diagnostics. Journal of Empirical Finance 10(4), 505-531. 
Lundbergh, S. and T. Teräsvirta (2002). Evaluating GARCH models. Journal of Econometrics 110(2), 417435.

Morgan, J. (1996). Riskmetrics (4th ed.). Technical Documents, New York.

Onatski, A. (2010). Determining the number of factors from empirical distribution of eigenvalues. The Review of Economics and Statistics 92(4), pp. 1004-1016.

Ramey, G. and V. A. Ramey (1995). Cross-country evidence on the link between volatility and growth. The American Economic Review 85(5), pp. 1138-1151.

Rich, R. and J. Tracy (2010). The relationship among expected inflation, disagreement, and uncertainty: Evidence from matched point and density forecasts. The Review of Economics and Statistics 92(1), 200207.

Sargent, T. and C. Sims (1977). Business cycle modelling without pretending to have too much a priori economic theory. In C. Sims (Ed.), New Methods in Business Cycle Research. Federal Reserve Bank of Minneapolis, Minneapolis.

Schaal, E. (2012). Uncertainty, productivity and unemployment in the great recession. Federal Reserve Bank of Minneapolis, Manuscript.

Stock, J. H. and M. W. Watson (2002). Macroeconomic forecasting using diffusion indexes. Journal of Business \& Economic Statistics 20(2), 147-162.

Zarnowitz, V. and L. A. Lambros (1987). Consensus and uncertainty in economic predictions. The Journal of Political Economy 95(3), 591-621. 


\section{Appendix}

\section{A Dataset and forecast error variance decomposition}

\begin{tabular}{|c|c|c|c|c|c|}
\hline & \multirow[b]{2}{*}{ Series } & \multirow[b]{2}{*}{ Transformation } & \multirow[b]{2}{*}{$\mathrm{R}^{2}$} & \multicolumn{2}{|c|}{ FEVD - Shock } \\
\hline & & & & 1 & 2 \\
\hline & \multicolumn{5}{|l|}{ Industrial production } \\
\hline 1 & Index of IP: Total & 3 & 0.64 & 1.00 & 0.00 \\
\hline 2 & Index of IP: Final products and nonindustrial supplies & 3 & 0.51 & 1.00 & 0.00 \\
\hline 3 & Index of IP: Final products & 3 & 0.41 & 1.00 & 0.00 \\
\hline 4 & Index of IP: Consumer goods & 3 & 0.29 & 1.00 & 0.00 \\
\hline 5 & Index of IP: Durable consumer goods & 3 & 0.26 & 0.98 & 0.02 \\
\hline 6 & Index of IP: Nondurable consumer goods & 3 & 0.04 & 0.90 & 0.10 \\
\hline 7 & Index of IP: Business equipment & 3 & 0.38 & 0.87 & 0.13 \\
\hline 8 & Index of IP: Materials & 3 & 0.60 & 0.98 & 0.02 \\
\hline 9 & Index of IP: Materials, nonenergy, durables & 3 & 0.64 & 0.90 & 0.10 \\
\hline 10 & Index of IP: Materials, nonenergy, nondurables & 3 & 0.42 & 0.54 & 0.46 \\
\hline 11 & Index of IP: Mfg & 3 & 0.65 & 1.00 & 0.00 \\
\hline 12 & Index of IP: Mfg, durables & 3 & 0.47 & 0.99 & 0.01 \\
\hline 13 & Index of IP: Mfg, nondurables & 3 & 0.38 & 0.88 & 0.12 \\
\hline 14 & Index of IP: Mining & 3 & 0.28 & 0.99 & 0.01 \\
\hline 15 & Index of IP: Utilities & 3 & 0.13 & 0.34 & 0.66 \\
\hline 16 & Index of IP: Energy, total & 3 & 0.14 & 0.72 & 0.28 \\
\hline 17 & Index of IP: Nonenergy, total & 3 & 0.64 & 1.00 & 0.00 \\
\hline 18 & Index of IP: Motor vehicles and parts (MVP) & 3 & 0.31 & 1.00 & 0.00 \\
\hline 19 & Index of IP: Computers, comm. equip. and semiconductors (CCS) & 3 & 0.10 & 0.98 & 0.02 \\
\hline 20 & Index of IP: Nonenergy excl CCS & 3 & 0.60 & 1.00 & 0.00 \\
\hline \multirow[t]{2}{*}{21} & Index of IP: Nonenergy excl CCS and MVP & 3 & 0.49 & 0.99 & 0.01 \\
\hline & \multicolumn{5}{|l|}{ Capacity utilisation } \\
\hline 22 & Capacity utilization: Total & 2 & 0.59 & 0.99 & 0.01 \\
\hline 23 & Capacity utilization: Mfg & 2 & 0.65 & 0.99 & 0.01 \\
\hline 24 & Capacity utilization: $\mathrm{Mfg}$, durables & 2 & 0.50 & 0.95 & 0.05 \\
\hline 25 & Capacity utilization: $\mathrm{Mfg}$, nondurables & 2 & 0.32 & 0.92 & 0.08 \\
\hline 26 & Capacity utilization: Mining & 2 & 0.32 & 0.97 & 0.03 \\
\hline 27 & Capacity utilization: Utilities & 2 & 0.04 & 0.25 & 0.75 \\
\hline 28 & Capacity utilization: Computers, comm. equip. and semiconductors & 2 & 0.10 & 0.94 & 0.06 \\
\hline 29 & Capacity utilization: Mfg excl CCS & 2 & 0.61 & 0.99 & 0.01 \\
\hline 30 & Purchasing managers index (PMI) & 3 & 0.26 & 1.00 & 0.00 \\
\hline \multirow[t]{2}{*}{31} & ISM mfg index: Production & 3 & 0.21 & 0.94 & 0.06 \\
\hline & Employment & & & & \\
\hline 32 & Index of help-wanted advertising & 3 & 0.15 & 0.12 & 0.88 \\
\hline 33 & No. of unemployed in the civ. Labor force (CLF) & 3 & 0.07 & 0.69 & 0.31 \\
\hline 34 & CLF employed: Total & 3 & 0.06 & 1.00 & 0.00 \\
\hline 35 & CLF employed: Nonagricultural industries & 3 & 0.06 & 0.93 & 0.07 \\
\hline
\end{tabular}




\begin{tabular}{|c|c|c|c|c|c|}
\hline & \multirow[b]{2}{*}{ Series } & \multirow[b]{2}{*}{ Transformation } & \multirow[b]{2}{*}{$\mathrm{R}^{2}$} & \multicolumn{2}{|c|}{ FEVD - Shock } \\
\hline & & & & 1 & 2 \\
\hline 36 & Mean duration of unemployment & 3 & 0.04 & 0.73 & 0.27 \\
\hline 37 & Persons unemployed less than 5 weeks & 3 & 0.05 & 0.29 & 0.71 \\
\hline 38 & Persons unemployed 5 to 14 weeks & 3 & 0.02 & 0.42 & 0.58 \\
\hline 39 & Persons unemployed 15 to 26 weeks & 3 & 0.06 & 0.28 & 0.72 \\
\hline 40 & Persons unemployed $15+$ weeks & 3 & 0.02 & 0.99 & 0.01 \\
\hline 41 & Avg weekly initial claims & 3 & 0.18 & 0.98 & 0.02 \\
\hline 42 & Employment on nonag. payrolls: Total & 3 & 0.42 & 0.92 & 0.08 \\
\hline 43 & Employment on nonag. payrolls: Total private & 3 & 0.51 & 0.92 & 0.08 \\
\hline 44 & Employment on nonag. payrolls: Goods-producing & 3 & 0.64 & 0.97 & 0.03 \\
\hline 45 & Employment on nonag. payrolls: Mining & 3 & 0.19 & 0.99 & 0.01 \\
\hline 46 & Employment on nonag. payrolls: Construction & 3 & 0.40 & 0.92 & 0.08 \\
\hline 47 & Employment on nonag. payrolls: Manufacturing & 3 & 0.57 & 0.99 & 0.01 \\
\hline 48 & Employment on nonag. payrolls: Manufacturing, durables & 3 & 0.56 & 0.99 & 0.01 \\
\hline 49 & Employment on nonag. payrolls: Manufacturing, nondurables & 3 & 0.30 & 0.99 & 0.01 \\
\hline 50 & Employment on nonag. payrolls: Service-producing & 3 & 0.16 & 0.99 & 0.01 \\
\hline 51 & Employment on nonag. payrolls: Utilities & 3 & 0.09 & 0.99 & 0.01 \\
\hline 52 & Employment on nonag. payrolls: Retail trade & 3 & 0.14 & 0.97 & 0.03 \\
\hline 53 & Employment on nonag. payrolls: Wholesale trade & 3 & 0.15 & 0.95 & 0.05 \\
\hline 54 & Employment on nonag. payrolls: Financial activities & 3 & 0.07 & 0.22 & 0.78 \\
\hline 55 & Employment on nonag. payrolls: Professional and bus. services & 3 & 0.07 & 0.01 & 0.99 \\
\hline 56 & Employment on nonag. payrolls: education and health services & 3 & 0.12 & 0.79 & 0.21 \\
\hline 57 & Employment on nonag. payrolls: Lesiure and hospitality & 3 & 0.02 & 0.89 & 0.11 \\
\hline 58 & Employment on nonag. payrolls: Other services & 3 & 0.08 & 0.81 & 0.19 \\
\hline 59 & Employment on nonag. payrolls: Government & 3 & 0.12 & 0.99 & 0.01 \\
\hline 60 & Avg weekly hrs. of production or nonsupervisory workers & 3 & 0.18 & 0.67 & 0.33 \\
\hline 61 & Avg weekly hrs. of PNW: Mfg & 3 & 0.13 & 0.85 & 0.15 \\
\hline 62 & Avg weekly overtime hrs. of PNW: Mfg & 3 & 0.19 & 0.97 & 0.03 \\
\hline \multirow[t]{2}{*}{63} & ISM mfg index: Employment & 3 & 0.22 & 0.95 & 0.05 \\
\hline & \multicolumn{5}{|l|}{ Sales } \\
\hline 64 & Sales: Mfg and trade-total (mil of chained $96 \$$ ) & 3 & 0.23 & 0.98 & 0.02 \\
\hline 65 & Sales: Mfg and trade-mfg, total (mil of chained $96 \$$ ) & 3 & 0.18 & 0.98 & 0.02 \\
\hline 66 & Sales: Mfg and trade-merchant wholesale (mil of chained 96\$) & 3 & 0.22 & 0.95 & 0.05 \\
\hline \multirow[t]{2}{*}{67} & Sales: Mfg and trade-retail trade (mil of chained $96 \$$ ) & 3 & 0.19 & 0.96 & 0.04 \\
\hline & \multicolumn{5}{|l|}{ Consumption } \\
\hline 68 & Personal cons. expenditure: Total (bil chained 96\$) & 3 & 0.21 & 1.00 & 0.00 \\
\hline 69 & Personal cons. expenditure: Durables (bil of chained 96\$) & 3 & 0.15 & 0.98 & 0.02 \\
\hline 70 & Personal cons. expenditure: Nondurables (bil of chained $96 \$$ ) & 3 & 0.14 & 1.00 & 0.00 \\
\hline
\end{tabular}




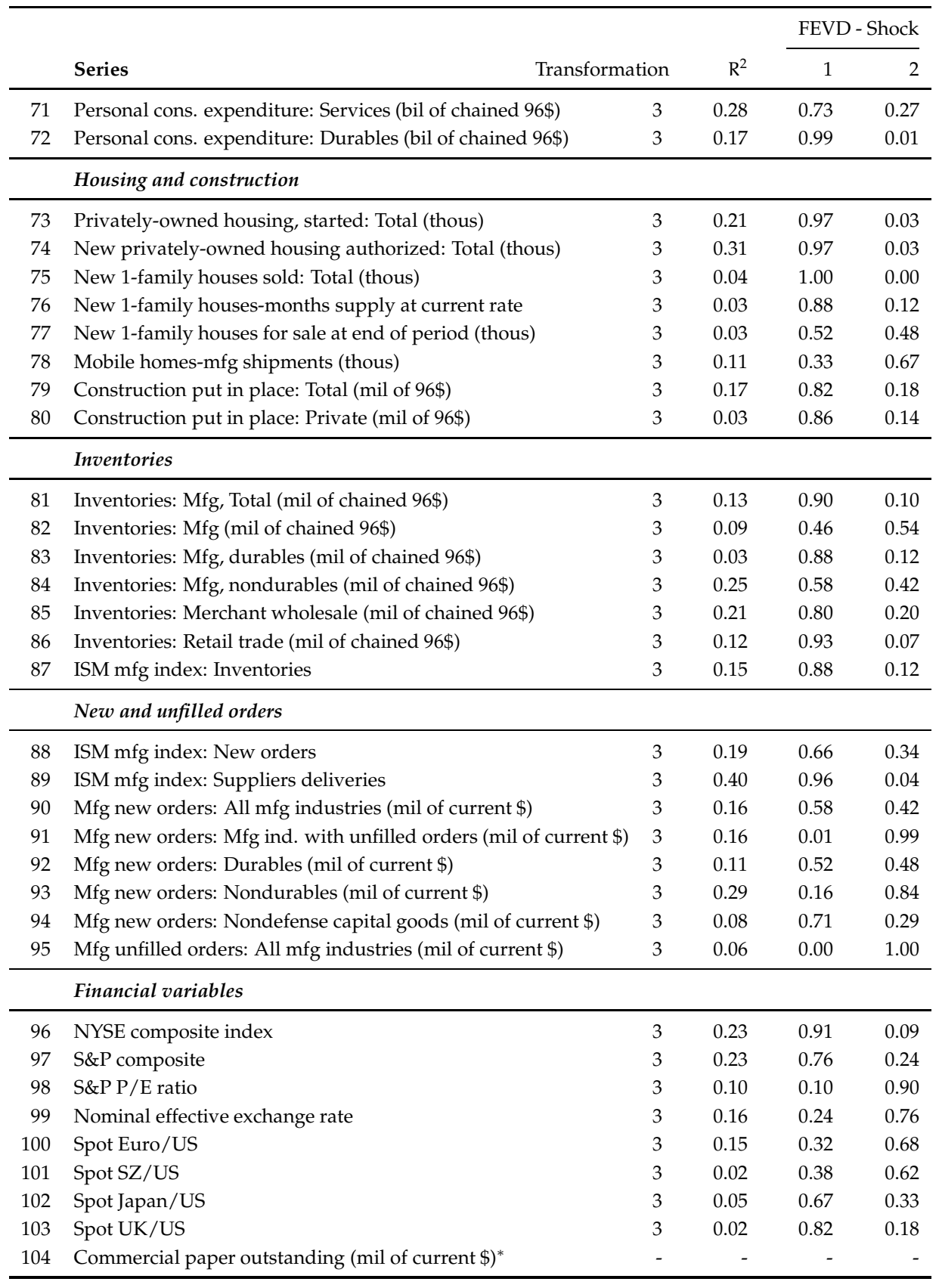




\begin{tabular}{|c|c|c|c|c|c|}
\hline & \multirow[b]{2}{*}{ Series } & \multirow[b]{2}{*}{ Transformation } & \multirow[b]{2}{*}{$R^{2}$} & \multicolumn{2}{|c|}{ FEVD - Shock } \\
\hline & & & & 1 & 2 \\
\hline & \multicolumn{5}{|l|}{ Interest rates } \\
\hline 105 & Interest rate: Federal funds rate & 2 & 0.40 & 0.99 & 0.01 \\
\hline 106 & Interest rate: U.S. 3-mo Treasury (sec. market) & 2 & 0.41 & 0.99 & 0.01 \\
\hline 107 & Interest rate: U.S. 6-mo Treasury (sec. market) & 2 & 0.37 & 0.99 & 0.01 \\
\hline 108 & Interest rate: 1-year Treasury & 2 & 0.35 & 0.99 & 0.01 \\
\hline 109 & Interest rate: 5-year Treasury (constant maturity) & 2 & 0.15 & 0.98 & 0.02 \\
\hline 110 & Interest rate: 7-year Treasury (constant maturity) & 2 & 0.10 & 0.96 & 0.04 \\
\hline 111 & Interest rate: 10 -year Treasury (constant maturity) & 2 & 0.07 & 0.95 & 0.05 \\
\hline 112 & Bond yield: Moodys AAA corporate & 2 & 0.03 & 0.94 & 0.06 \\
\hline \multirow[t]{2}{*}{113} & Bond yield: Moodys BAA corporate & 2 & 0.02 & 0.32 & 0.68 \\
\hline & \multicolumn{5}{|l|}{ Monetary variables } \\
\hline 114 & M1 (bil of current \$) & 3 & 0.27 & 0.06 & 0.94 \\
\hline 115 & M2 (bil of current \$) & 3 & 0.12 & 0.06 & 0.94 \\
\hline 116 & M3 (bil of current \$) & 3 & 0.14 & 0.02 & 0.98 \\
\hline 117 & Monetary base, adj. for reserve requirement $(\mathrm{rr})$ changes (bil of $\$)^{*}$ & - & - & - & - \\
\hline 118 & Depository institutions reserves: total (adj. for rr changes)* & - & - & - & - \\
\hline 119 & Depository institutions: nonborrowed (adj. for rr changes)* ${ }^{*}$ & - & - & - & - \\
\hline 120 & Loans and securities at all comm banks: Total (mil of current $\$$ ) & 3 & 0.21 & 0.37 & 0.63 \\
\hline 121 & Loans and securities at all comm banks: Securities, total (mil of \$) & 3 & 0.13 & 0.37 & 0.63 \\
\hline 122 & Loans and securities at all comm banks: Securities, U.S. govt (mil of \$) & 3 & 0.29 & 0.76 & 0.24 \\
\hline 123 & Loans and securities at all comm banks: Real estate loans (mil of \$) & 3 & 0.25 & 0.08 & 0.92 \\
\hline 124 & Loans and securities at all comm banks: Comm and Ind loans (mil of \$) & 3 & 0.16 & 0.12 & 0.88 \\
\hline 125 & Loans and securities comm banks: consumer loans (mil of $\$)^{*}$ & - & - & - & - \\
\hline \multirow[t]{2}{*}{126} & Delinquency rate on bank-held consumer installment loans* & - & - & - & - \\
\hline & \multicolumn{5}{|l|}{ Prices } \\
\hline 127 & PPI: Finished goods (1982 = 100 for all PPI data) & 3 & 0.69 & 0.06 & 0.94 \\
\hline 128 & PPI: Finished consumer goods & 3 & 0.73 & 0.05 & 0.95 \\
\hline 129 & PPI: Intermediate materials & 3 & 0.65 & 0.06 & 0.94 \\
\hline 130 & PPI: Crude materials & 3 & 0.51 & 0.05 & 0.95 \\
\hline 131 & PPI: Finished goods excl food & 3 & 0.70 & 0.00 & 1.00 \\
\hline 132 & Index of sensitive materials prices* & - & - & - & - \\
\hline 133 & CPI: All items (urban) & 3 & 0.75 & 0.27 & 0.73 \\
\hline 134 & CPI: Food and beverages & 3 & 0.25 & 0.93 & 0.07 \\
\hline 135 & CPI: Housing & 3 & 0.32 & 0.99 & 0.01 \\
\hline 136 & CPI: Apparel & 3 & 0.16 & 0.84 & 0.16 \\
\hline 137 & CPI: Transportation & 3 & 0.76 & 0.02 & 0.98 \\
\hline 138 & CPI: Medical care & 3 & 0.26 & 0.95 & 0.05 \\
\hline 139 & CPI: Commodities & 3 & 0.85 & 0.06 & 0.94 \\
\hline 140 & CPI: Commodities, durables & 3 & 0.04 & 0.67 & 0.33 \\
\hline
\end{tabular}




\begin{tabular}{|c|c|c|c|c|c|}
\hline & \multirow[b]{2}{*}{ Transforma } & & \multirow[b]{2}{*}{$\mathrm{R}^{2}$} & \multicolumn{2}{|c|}{ FEVD - Shock } \\
\hline & & ion & & 1 & 2 \\
\hline 141 & CPI: Services & 3 & 0.34 & 0.98 & 0.02 \\
\hline 142 & CPI: All items less food & 3 & 0.71 & 0.22 & 0.78 \\
\hline 143 & CPI: All items less shelter & 3 & 0.82 & 0.13 & 0.87 \\
\hline 144 & CPI: All items less medical care & 3 & 0.76 & 0.26 & 0.74 \\
\hline 145 & CPI: All items less food and energy & 3 & 0.41 & 0.96 & 0.04 \\
\hline 146 & Price of gold (\$/oz) on the London market (recorded in the p.m.) & 3 & 0.25 & 0.71 & 0.29 \\
\hline 147 & PCE chain weight price index: Total & 3 & 0.63 & 0.24 & 0.76 \\
\hline 148 & PCE prices: Total excl. food and energy & 3 & 0.06 & 0.97 & 0.03 \\
\hline 149 & PCE prices: Durables & 3 & 0.04 & 1.00 & 0.00 \\
\hline 150 & PCE prices: Nondurables & 3 & 0.84 & 0.01 & 0.99 \\
\hline \multirow[t]{2}{*}{151} & PCE prices: Services & 3 & 0.09 & 0.99 & 0.01 \\
\hline & \multicolumn{5}{|l|}{ Wages } \\
\hline 152 & Avg hourly earnings: Total nonagricultura (current \$) & 3 & 0.35 & 0.83 & 0.17 \\
\hline 153 & Avg hourly earnings: Construction (current \$) & 3 & 0.26 & 0.84 & 0.16 \\
\hline 154 & Avg hourly earnings: Mfg (current \$) & 3 & 0.35 & 0.93 & 0.07 \\
\hline 155 & Avg hourly earnings: Finance, insurance, and real estate (current \$) & 3 & 0.15 & 0.96 & 0.04 \\
\hline 156 & Avg hourly earnings: Professional and business services (current \$) & 3 & 0.07 & 0.44 & 0.56 \\
\hline 157 & Avg hourly earnings: Education and health services (current \$) & 3 & 0.27 & 0.96 & 0.04 \\
\hline \multirow[t]{2}{*}{158} & Avg hourly earnings: Other services (current \$) & 3 & 0.24 & 1.00 & 0.00 \\
\hline & \multicolumn{5}{|l|}{ Merchandise ex-and imports } \\
\hline 159 & Total merchandise exports (FAS value) (mil of \$) & 3 & 0.24 & 0.87 & 0.13 \\
\hline 160 & Total merchandise imports (CIF value) (mil of \$) (NSA) & 3 & 0.39 & 1.00 & 0.00 \\
\hline \multirow[t]{2}{*}{161} & Total merchandise imports (customs value) (mil of \$) & 3 & 0.38 & 1.00 & 0.00 \\
\hline & \multicolumn{5}{|l|}{ Business outlook } \\
\hline 162 & Philadelphia Fed business outlook: General activity & 2 & 0.07 & 0.28 & 0.72 \\
\hline 163 & Outlook: New orders & 2 & 0.13 & 0.68 & 0.32 \\
\hline 164 & Outlook: Shipments & 2 & 0.10 & 0.70 & 0.30 \\
\hline 165 & Outlook: Inventories & 2 & 0.11 & 0.83 & 0.17 \\
\hline 166 & Outlook: Unfilled orders & 2 & 0.10 & 0.97 & 0.03 \\
\hline 167 & Outlook: Prices paid & 2 & 0.12 & 0.01 & 0.99 \\
\hline 168 & Outlook: Prices received & 2 & 0.05 & 0.69 & 0.31 \\
\hline 169 & Outlook Employment & 2 & 0.03 & 0.95 & 0.05 \\
\hline 170 & Outlook: Work hours & 2 & 0.04 & 0.94 & 0.06 \\
\hline 171 & Federal govt deficit or surplus (mil of current \$) & 2 & 0.06 & 0.46 & 0.54 \\
\hline
\end{tabular}

Note: Variables marked with a ' $*$ ' are not available for the full sample period and therefore excluded from the analysis. The transformations applied to the data and determined in the column 'Transformation' are explained in greater detail below. Columns labeled ' $R^{2 \prime}$ report the $R^{2}$ of factor models based on two fundamental factors. Columns ' 1 ' and ' 2 ' display forecast error variances (12-month-ahead) explained by the first or the second fundamental shock.

Table A.1: Description of the dataset and forecast error variance decomposition 


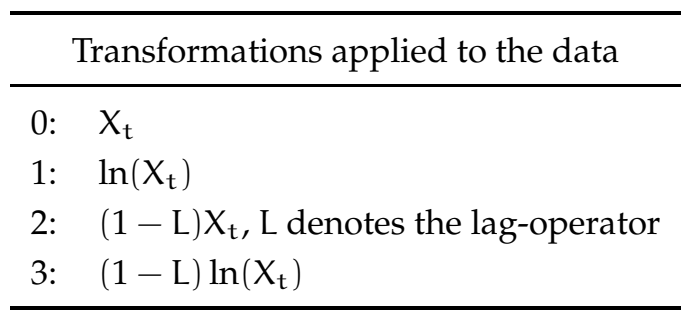

Table A.2: Transformations

Remark 1: Whenever a series has not been available in NAICS classification scheme for the entire sample period, missing values have been linked with data based on the SIC classification scheme.

Remark 2: Series 32 has been published only until 2010M7. It has been linked with the Help Wanted Online Index published by the Conference Board.

Remark 3: Whenever a series denoted in mil. of chained 2005 \$ has not been available for the entire sample period, missing values have been linked with data published in mil. of chained 1996 \$.

Remark 4: Series 116 has been replaced by the monetary aggregates index published by the Federal Reserve Bank of St. Louis (monetary aggregate (all), sum, comparable to old index M3).

\section{B Estimation of the dynamic factor model}

Doz et al. (2012) introduce a Quasi Maximum Likelihood estimation procedure for the so-called 'approximate' factor model where the idiosyncratic components $\xi_{t}$ in (7) and residuals $\epsilon_{t}$ in (8) may be weakly correlated. Doz et al. (2012) show that the factors are estimated consistently by Maximum Likelihood if $n$ and T are large even if serial correlation and cross-sectional correlation of the idiosyncratic components is omitted. The estimation procedure is based on the EM-algorithm which we initialize using an estimate of $\hat{f}_{t}$ obtained from principal components. Given this initialization we iterate between the following steps.

\section{M-step:}

- Obtain the loadings matrix $\hat{\lambda}$ by regressing $X_{t}$ on $\hat{f}_{t}$. 
- Estimate the idiosyncratic components from $\hat{\varepsilon}_{t}=X_{t}-\hat{\lambda} \hat{f}_{t}$. Further, evaluate the corresponding covariance matrix of the idiosyncratic components denoted by $\hat{\delta}_{\xi}$. Restrict the off-diagonal elements to zero as proposed by Doz et al. (2012).

- Estimate the $h$-th order VAR in $f_{t}$ using $\hat{f}_{t}$.

- Estimate the covariance of the residuals $\hat{\mathcal{S}}_{\epsilon}$.

\section{E-step:}

- $\xi_{\mathrm{t}}$ and $\epsilon_{\mathrm{t}}$ are both assumed to be normally distributed and independent from each other.

- Apply the Kalman filter given the parameter estimates from the M-step and update the estimated factors $\hat{f}_{\mathrm{t}}$.

- The Likelihood function is evaluated by means of the Kalman filter.

Iterate forward between the E-step and the M-step until convergence is reached.

We apply an eigenvalue decomposition to the final estimate of the covariance matrix $\hat{\delta}_{\epsilon}$. Let $M$ be a matrix containing the eigenvalues on the main diagonal and zeros elsewhere. The corresponding eigenvectors are stored in the matrix $Q$. Thus, $R$ is given by

$$
\hat{\mathrm{R}}=\mathrm{Q} \mathrm{M}^{\frac{1}{2}},
$$

and

$$
\hat{u}_{t}=\hat{\epsilon}_{t} Q M^{\frac{1}{2}} .
$$

\section{Tests for the number of factors}

In table C.1 we present the number of common factors indicated by different information criteria. Given our previous results, it appears reasonable to fix the maximum number of common factors to $k_{\max }=4$. The criteria of Bai and $\mathrm{Ng}$ (2002) suggest $\mathrm{k}=4$. Most likely these criteria overestimate the number of factors when the idiosyncratic components are correlated which is probably the case in our dataset since it contains 
subcategories of a number of variables (see also Onatski, 2010; Jurado et al., 2014). Bai and $\mathrm{Ng}$ (2008) suggest the criterion $\mathrm{IC}_{\mathrm{BN} 08}$ which works well particularly when idiosyncratic components are cross correlated. According to $\mathrm{IC}_{\mathrm{BN} 08}$ there are three factors. The test of Onatski (2010) (IC $\left.\mathrm{IN}_{\mathrm{ON} 10}\right)$ and the criteria of Ahn and Horenstein (2013) (ER, GR) uniformly indicate one common factor although our previous analysis suggests that one factor does not represent the dataset in a satisfactory manner. While the former criterion is more appropriate when idiosyncratic components feature autocorrelation, the latter two are less sensitive to the choice of $k_{\max }$.

\begin{tabular}{ccccccc}
\hline $\mathrm{IC}_{\mathrm{p} 1}$ & $\mathrm{IC}_{\mathrm{p} 2}$ & $\mathrm{IC}_{\mathrm{p} 3}$ & $\mathrm{IC}_{\mathrm{BN} 08}$ & $\mathrm{IC}_{\mathrm{ON} 10}$ & $\mathrm{ER}$ & $\mathrm{GR}$ \\
4 & 4 & 4 & 3 & 1 & 1 & 1
\end{tabular}

Note: This table displays the number of fundamental factors determined by means of the $\mathrm{IC}_{\mathrm{p}}$ of Bai and $\mathrm{Ng}$ (2002) and $\mathrm{IC}_{\mathrm{BN} 08}$ of Bai and $\mathrm{Ng}$ (2008). Calculations are based on a maximum number of factors $k_{\max }=4$. IC $\mathrm{ON} 10_{0}$ reports the number of factors indicated by the procedure of Onatski (2010), while ER and GR represent the results of the procedures proposed by Ahn and Horenstein (2013).

Table C.1: Tests to determine the number of common factors

We may also use tests to determine the number of fundamental shocks in a general dynamic factor model where the number of factors may differ from the number of fundamental shocks. Since in this case the results depend on the number of factors, we calculate the tests for various numbers of factors. Table C.2 reveals that the criterion proposed in Bai and $\mathrm{Ng}$ (2007) points at two to three fundamental shocks while the procedure of Hallin and Liška (2007) indicates up to two fundamental shocks. Notably, the results are largely independent from the number of factors, i.e. adding more common factors to the model hardly affects the estimated number of fundamental shocks.

\begin{tabular}{cccccccc}
\hline Number of factors & 2 & 4 & 6 & 8 & 10 & 12 & 14 \\
\hline Bai and $\mathrm{Ng}(2007)$ & 2 & 2 & 3 & 3 & 3 & 2 & 2 \\
Hallin and Liška (2007) & 1 & 2 & 2 & 2 & 2 & 2 & 2 \\
\hline
\end{tabular}

Note: The upper panel reports the number of fundamental shocks determined by the criterion of Bai and $\mathrm{Ng}$ (2007), the lower panel displays the results for the criterion of Hallin and Liška (2007). We conduct the tests using six lags of $f$.

Table C.2: Tests to determine the number of fundamental shocks 


\section{Bootstrap procedure for impulse responses of the fac- tor model}

We employ a bootstrap procedure similar to that proposed by Forni, Giannone, Lippi, and Reichlin (2007) and Giannone, Reichlin, and Sala (2002) to compute confidence bounds for responses of individual uncertainty measures to fundamental shocks $u_{t}$ in figures 3 and 4 . Having estimated the factor model we make use of the following quantities: $\hat{\lambda}, \hat{\xi}_{t}, \hat{\psi}(\mathrm{L})$ and $\hat{\epsilon}_{\mathrm{t}}$.

- To simulate the factors, denoted by $\widetilde{f}_{t}$, we apply the residual based bootstrap and draw with replacement from centered residuals of the VAR in the factors: $\hat{\epsilon}_{t}-\bar{\epsilon}$, where $\bar{\epsilon}$ is a vector of sample averages.

- The estimated parameters in $\hat{\psi}(\mathrm{L})$ are then used to simulate a new dataset from $\widetilde{X}_{t}=\hat{\lambda} \tilde{f}_{t}+\hat{\xi}_{t}$. We do not permute $\hat{\xi}_{t}$ because the major part of estimation uncertainty is related to the estimation of the VAR in the factors (compare Giannone et al., 2002, on this point).

- Use $\widetilde{X}_{t}$ and re-estimate the factor model in equations (7) and (8) in section 3.2 to obtain a new set of parameters and impulse responses.

We obtain 500 draws of each impulse response function by repeated execution of this bootstrap procedure.

\section{E Robustness: Alternative rotation of fundamental shocks}

In contrast to the baseline rotation, we maximize the variance share explained by shock 2 for variables representing oil and commodity price uncertainty. To be specific, D in the target function (12) selects the following individual uncertainty measures: total energy production (series 16), PPI of crude materials (series 130), CPI of commodities (series 139 ) and CPI of durable commodities (series 140). In the following we compare the impulse response functions obtained from this alternative rotation with those from the baseline rotation. Since the impulse responses are almost identical the interpretation of the two fundamental shocks appears to be robust to a change of the identification strategy. 
Response to shock 1
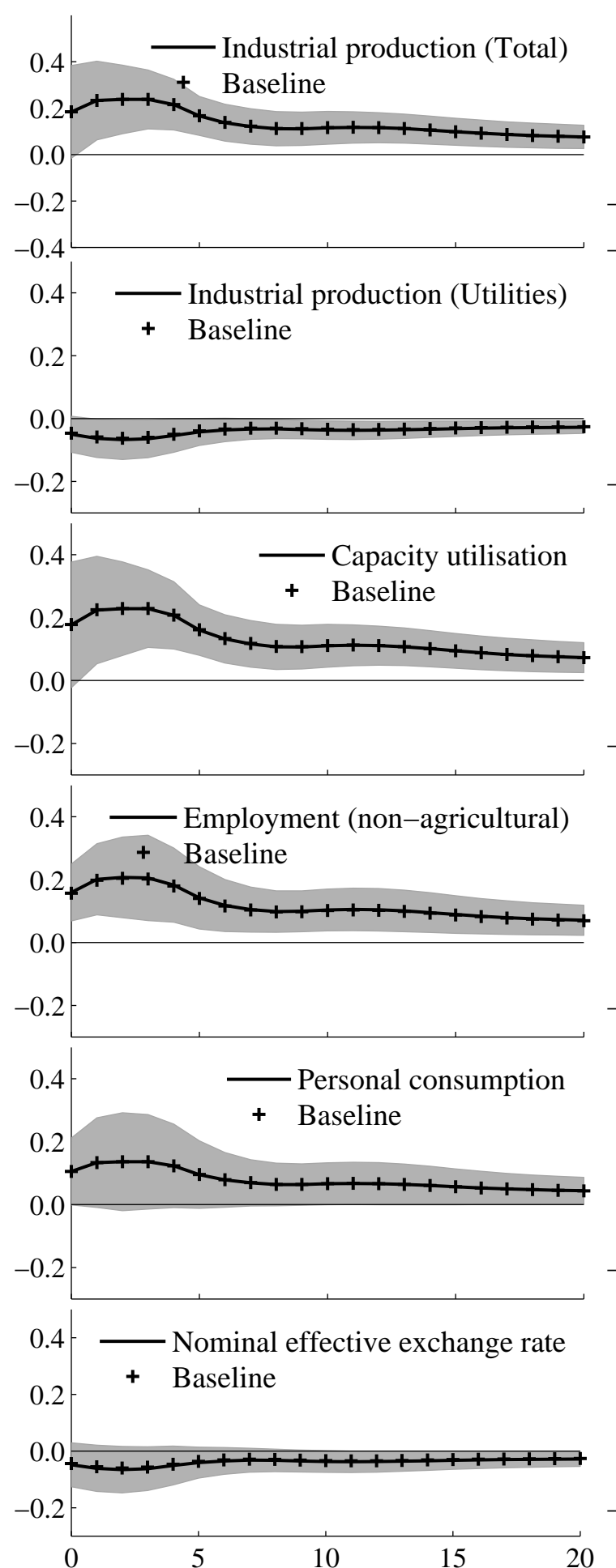

Response to shock 2
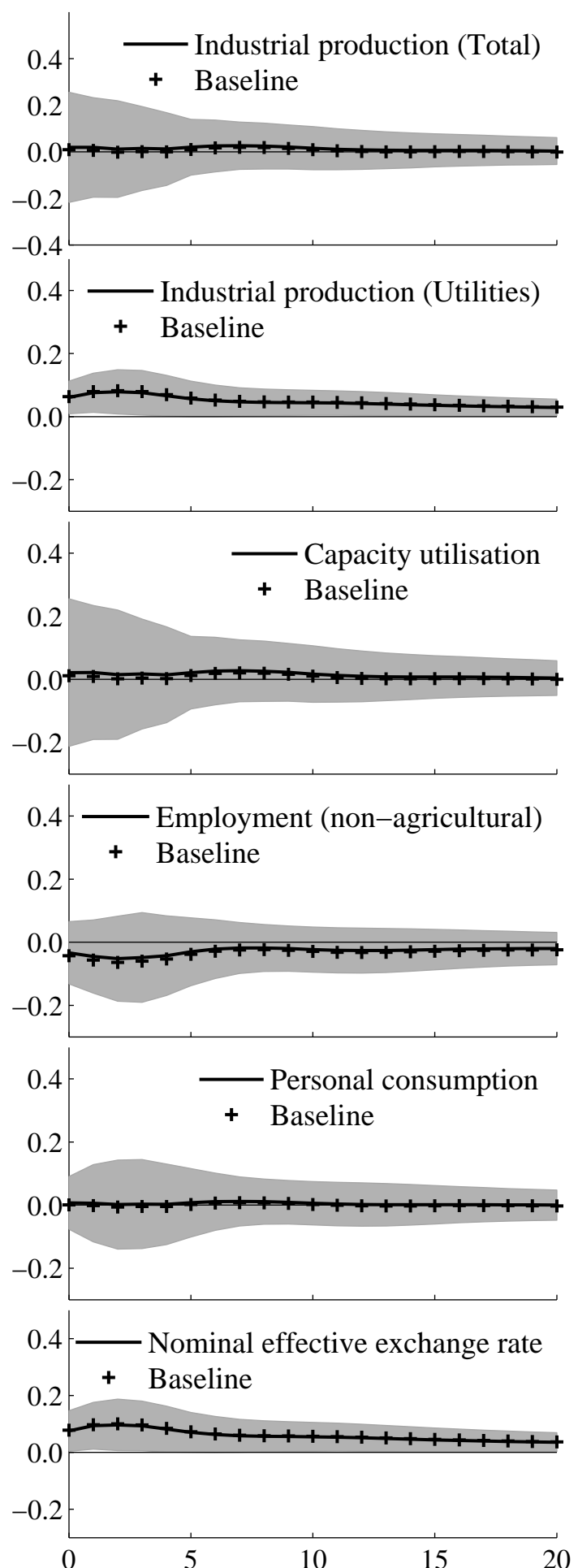

Note: Impulse responses to the first fundamental shock (left column) and to the second fundamental shock (right column) identified with the alternative rotation are indicated by the bold lines. Impulse responses from the baseline rotation are marked with crosses. Shaded areas indicate bootstrapped $90 \%$ confidence intervals.

Figure E.1: Impulse responses of individual uncertainty measures for alternative identification strategies (1) 
Response to shock 1
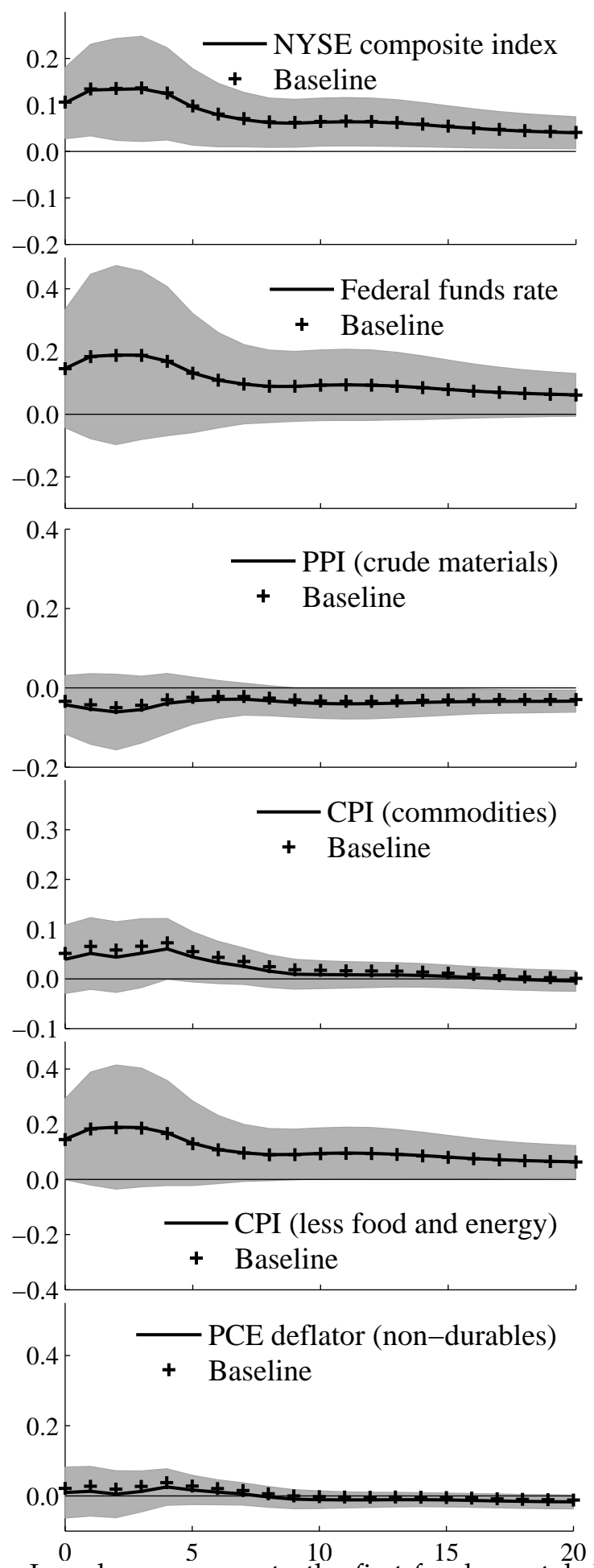

Response to shock 2
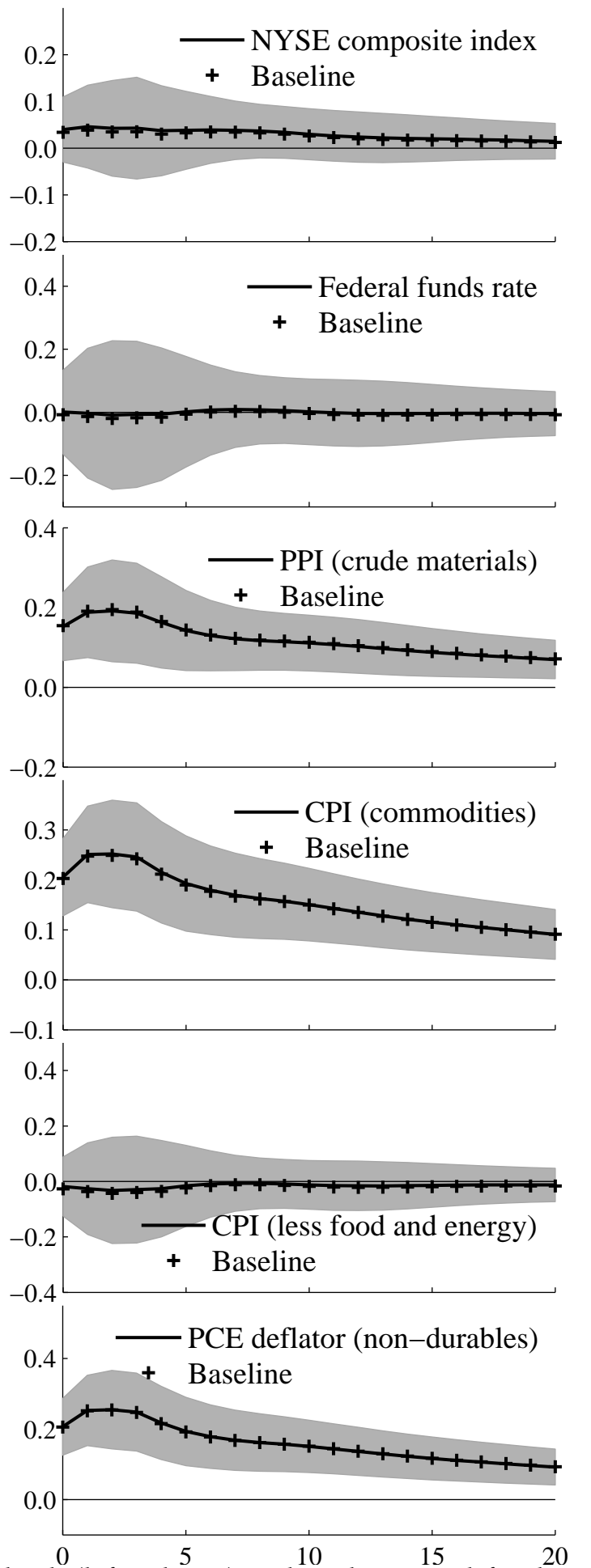

Note: Impulse responses to the first fundamental shock (left column) and to the second fundamental shock (right column) identified with the alternative rotation are indicated by the bold lines. Impulse responses from the baseline rotation are marked with crosses. Shaded areas indicate bootstrapped $90 \%$ confidence intervals.

Figure E.2: Impulse responses of individual uncertainty measures for alternative identification strategies (2) 


\section{F Identification of the indicators of macroeconomic un- certainty}

In the following, we present the rotation strategy that we use to separately identify the two factors. The rotation matrix $G$ may be used to rewrite the factor model in (7) such that

$$
X_{t}=\lambda^{*} G^{\prime} f_{t}^{*}+\xi_{t}
$$

with $\mathrm{GG}^{\prime}=\mathrm{I}$. To derive the covariance matrix of the factors we rewrite the process in (8) as a first order VAR

$$
\mathrm{F}_{\mathrm{t}}^{*}=\mathcal{A} \mathrm{F}_{\mathrm{t}-1}^{*}+\mathcal{R U _ { \mathrm { t } }}
$$

where $F_{t}^{*}=\left(f_{t}^{*^{\prime}}, f_{t-1}^{*^{\prime}}, \ldots, f_{t-h+1}^{*^{\prime}}\right)^{\prime}$ denotes a vector containing the stacked factors. It follows that the residual vector $U_{t}=\left(u_{t}^{\prime}, 0 \ldots, 0\right)^{\prime}, \mathcal{R}=\left(R^{\prime}, 0, \ldots, 0\right)^{\prime}$, and $\mathcal{A}$ have the usual companion form. The vectorized covariance matrix $\mathcal{S}_{\mathrm{F}}^{*}$ of the stacked factors $\mathrm{F}_{\mathrm{t}}^{*}$ can be expressed as

$$
\operatorname{vec}\left(\mathcal{S}_{\mathrm{F}}^{*}\right)=\left(\mathrm{I}_{(\mathrm{rh})^{2}}-[\mathcal{A} \otimes \mathcal{A}]\right)^{-1} \operatorname{vec}\left(\mathcal{R R}^{\prime}\right)
$$

where the covariance matrix $\mathcal{S}_{f}^{*}$ of the factors $f_{t}^{*}$ corresponds to the upper left $k \times k$ sub matrix of $\mathcal{S}_{\mathrm{F}}^{*}$. We define the corresponding covariance matrix of the rotated factors $f_{t}=G^{\prime} f_{t}^{*}$ as

$$
\mathcal{S}_{f}=G^{\prime} \mathcal{S}_{f}^{*} \mathrm{G}
$$

Further, we introduce the matrix $S_{f_{1}}\left(S_{f_{2}}\right)$ which is a zero matrix except for the upper left (lower right) hand side element which equals the corresponding element of $\mathcal{S}_{f}$. The $i$-th diagonal element of the covariance matrix of the idiosyncratic processes $\mathcal{S}_{\xi}$ is denoted as $\mathcal{S}_{\xi, i}$ and the $i$-th row of loadings matrix $\lambda$ as $\lambda_{i}$. To determine the rotation matrix $G$ we maximize the target function

$$
k(G)=\frac{\sum_{i \in D} \lambda_{i}^{*} G \mathcal{S}_{f_{1}} G^{\prime} \lambda_{i}^{*^{\prime}}}{\sum_{i \in D}\left(\lambda_{i}^{*} G \mathcal{S}_{f_{1}} G^{\prime} \lambda_{i}^{*^{\prime}}+\lambda_{i}^{*} G \mathcal{S}_{f_{2}} G^{\prime} \lambda_{i}^{*^{\prime}}+\mathcal{S}_{\xi, i}\right)} .
$$


This function summarizes the variance proportions explained by the first factor for a selection of individual uncertainty measures defined in $\mathrm{D}$. We define this selection matrix again such that it selects the uncertainty measures associated with output (series 1 to 31). This rotation procedure thus maximizes the variance proportions of selected individual uncertainty measures which are explained by a particular factor's variance (see also Kose et al., 2012). Since the factors are not restricted to be orthogonal the denominator in (19) consists of the sum of the variance proportions explained by the two factors individually which can deviate from the variance proportion explained by the two factors jointly $\left(\lambda_{i}^{*} G S_{f} G^{\prime} \lambda_{i}^{*}\right)$.

\section{G Robustness: Macroeconomic uncertainty derived from out-of-sample forecast errors}

The indicators of macroeconomic uncertainty in section 4.3 are conditioned on insample forecast errors since the factor model's parameters are estimated using full sample information. In this section we estimate the predictive factors using a recursive window initialized with observations from the first five years. Out-of-sample forecast errors are then generated by estimating the forecast equation (1) in a recursive fashion. Individual uncertainty measures and the indicators of macroeconomic uncertainty are evaluated as described in section 3.1. Figure G.1 displays such alternative indicators along with the corresponding measures based on in-sample forecast errors. Although forecasts in early periods may suffer from a small sample size the indicators co-move closely. The correlations are 0.95 and 0.9 , respectively. 
Business cycle uncertainty
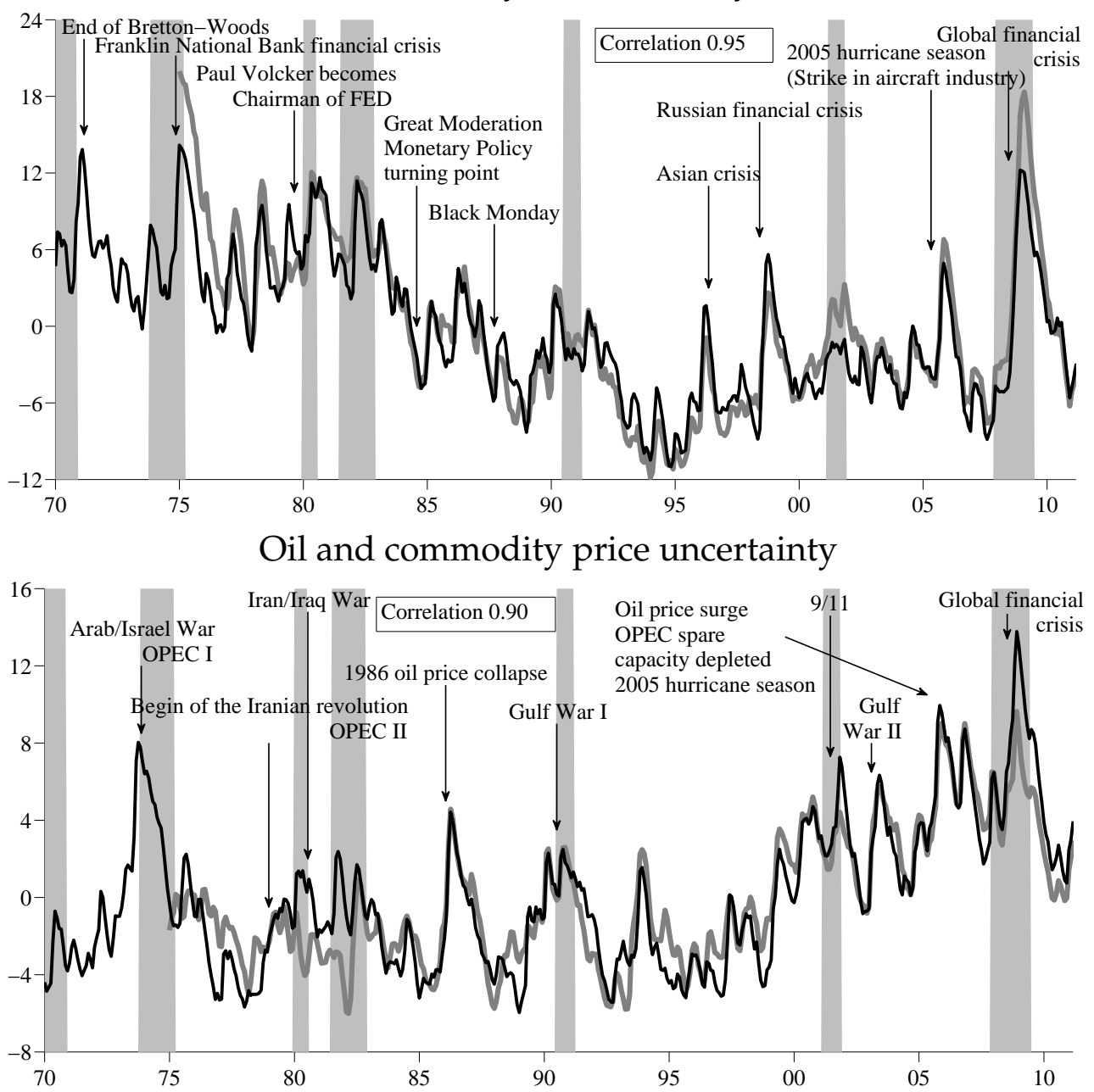

The upper panel depicts business cycle uncertainty and the lower panel depicts oil and commodity price uncertainty. NBER recession dates are indicated by the shaded areas. In both panels the black line represents our baseline estimates based on in-sample forecast errors while the bold grey line represents estimates based on recursive out-of-sample forecast errors.

Figure G.1: Indicators of macroeconomic uncertainty from in-sample and out-of-sample forecast errors. 


\section{H Comparison to alternative measures of macroeconomic uncertainty}
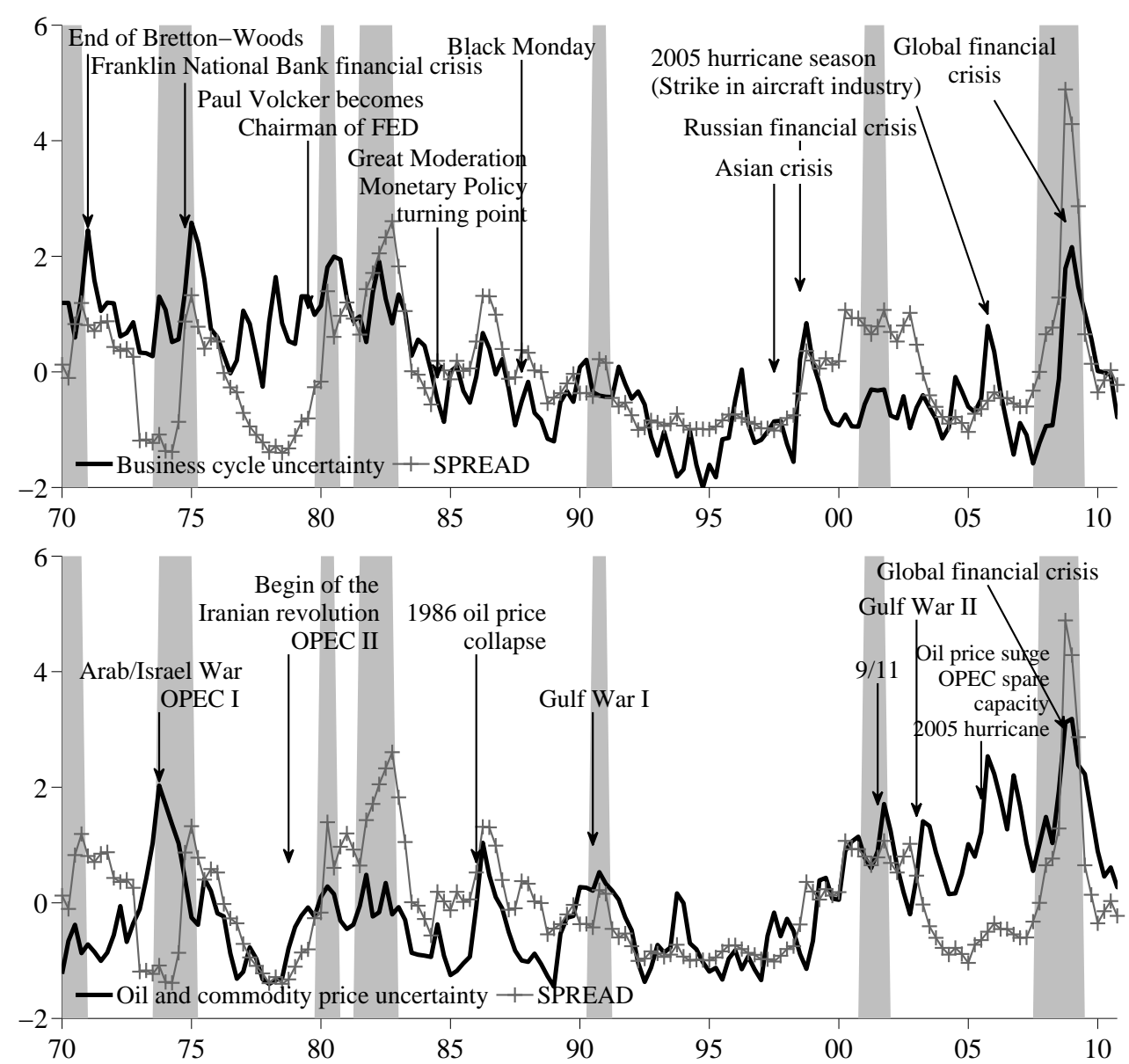

The upper panel depicts business cycle uncertainty and the lower panel oil and commodity price uncertainty. The crossed (grey) line represents the Baa corporate bond spread (SPREAD). To facilitate the interpretation of the graph, we calculate quarterly averages of the monthly series and standardize all series. NBER recession dates are indicated by the shaded areas.

Figure H.1: Indicators of macroeconomic uncertainty and SPREAD 

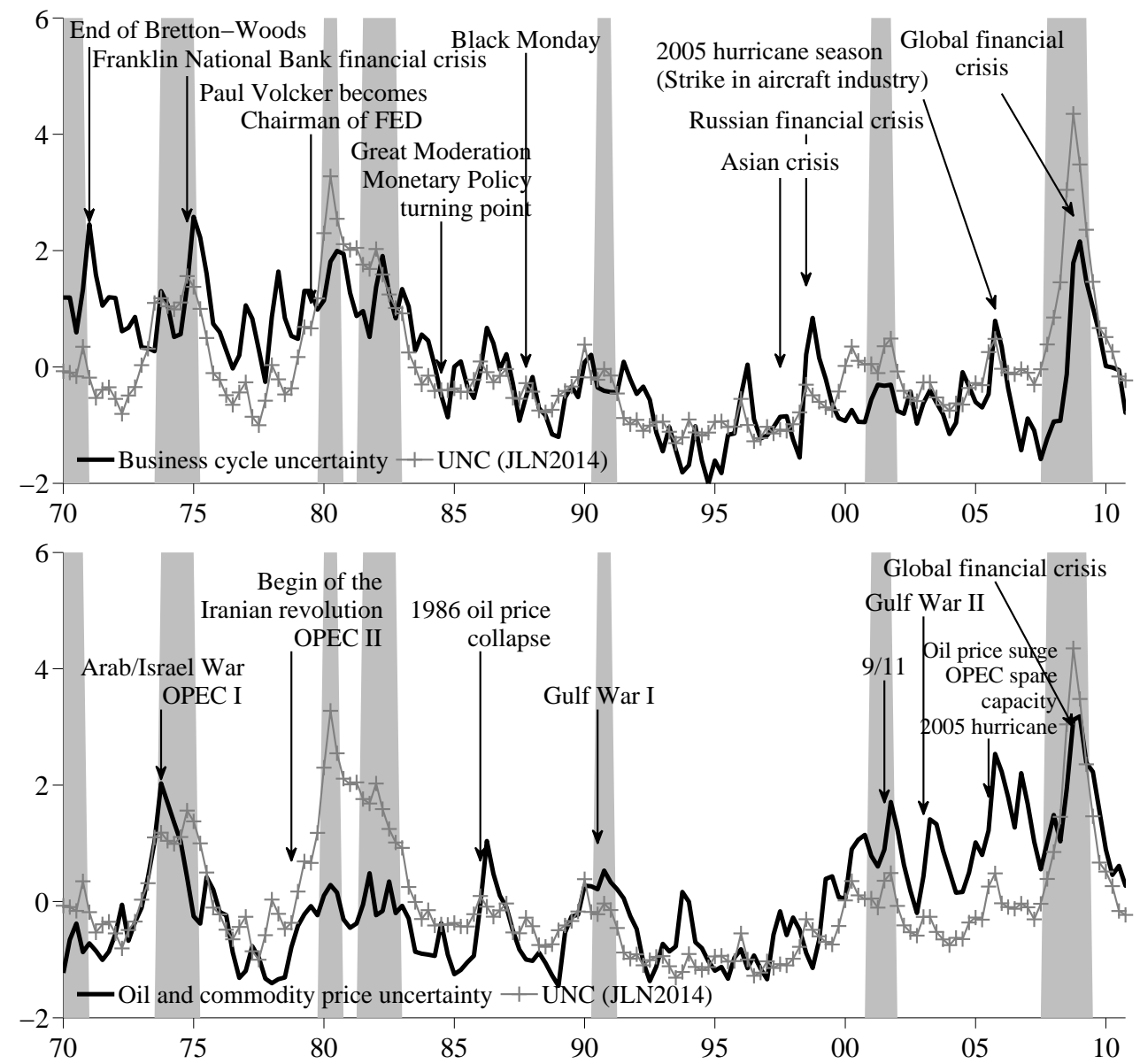

The upper panel depicts business cycle uncertainty and the lower panel oil and commodity price uncertainty. The crossed (grey) line represents the measure of Jurado et al. (2014) which is based on the factor with the largest explanatory power. To facilitate the interpretation of the graph, we calculate quarterly averages of the monthly series and standardize all series. NBER recession dates are indicated by the shaded areas.

Figure H.2: Indicators of macroeconomic uncertainty and JLN 

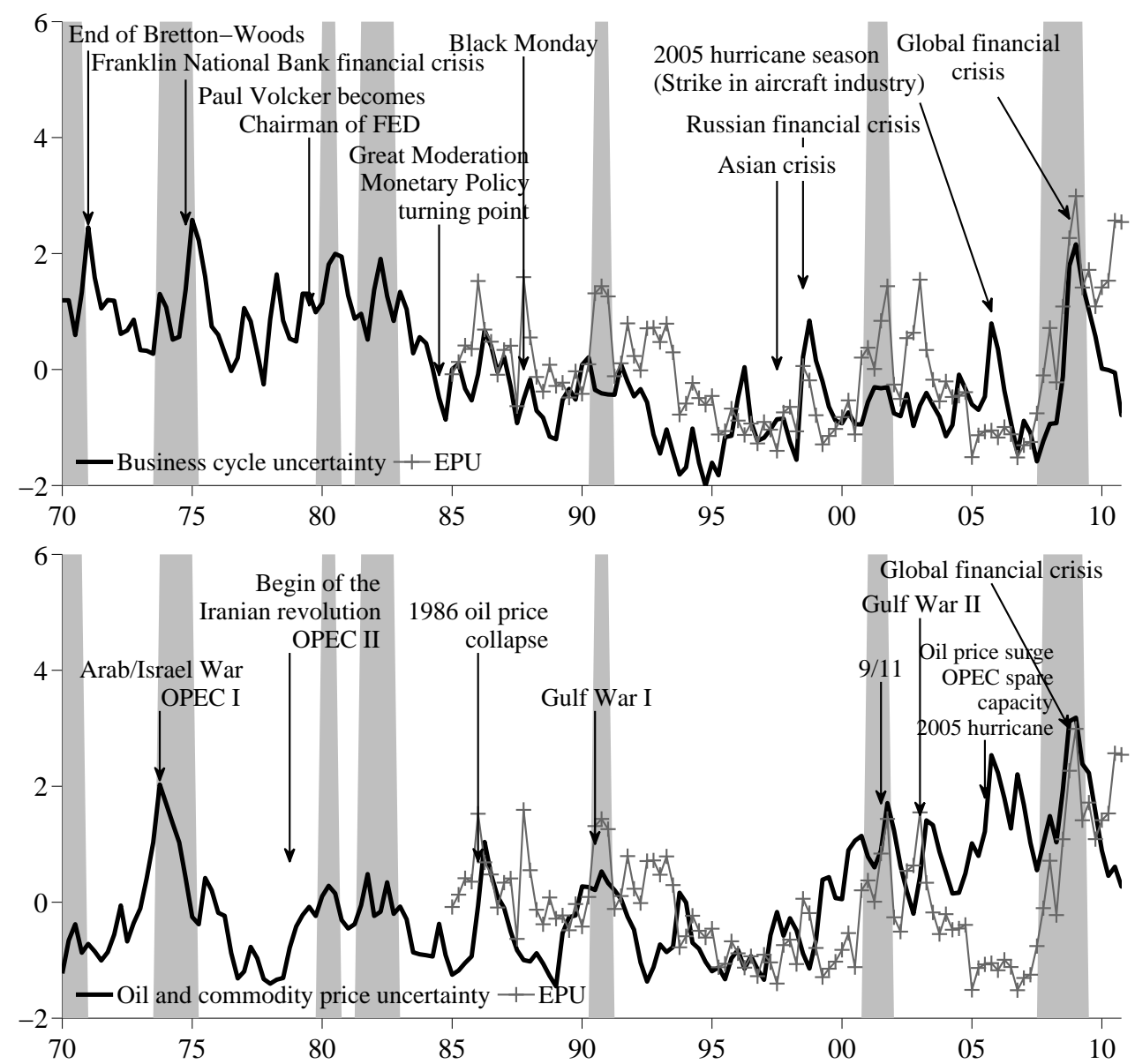

Note: The upper panel depicts the business cycle uncertainty and the lower panel the oil and commodity price uncertainty. The crossed (grey) line represents economic policy uncertainty (EPU). To facilitate the interpretation of the graph, we calculate quarterly averages of the monthly series and standardize all series. NBER recession dates are indicated by the shaded areas.

Figure H.3: Indicators of macroeconomic uncertainty EPU 


\section{Dynamic relation of VXO, SPREAD, JLN, and EPU}

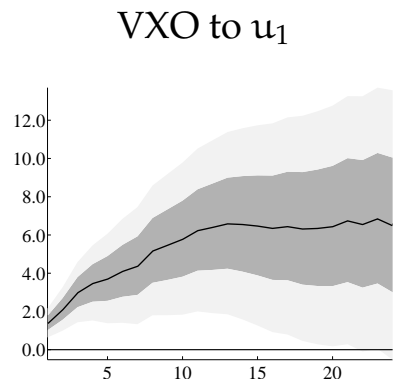

JLN to $\mathrm{u}_{1}$
$\mathrm{VXO}$ to $\mathrm{u}_{2}$

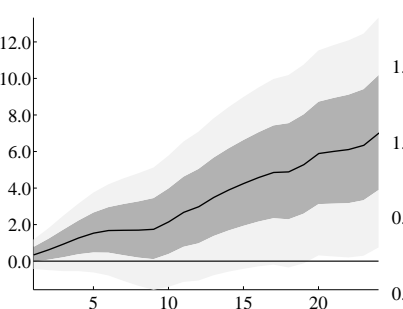

JLN to $u_{2}$

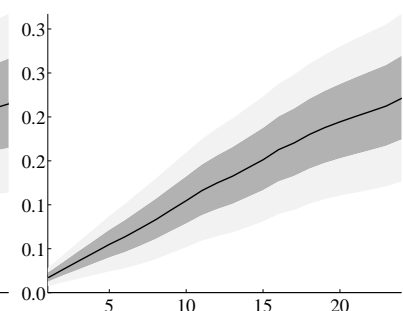

SPREAD to $u_{1}$

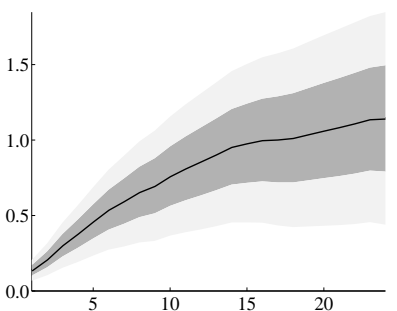

EPU to $u_{1}$

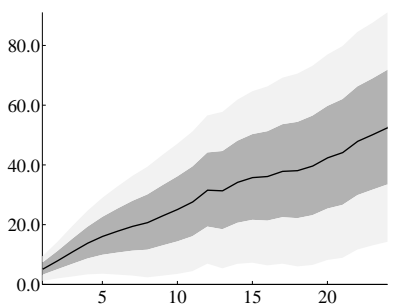

SPREAD to $u_{2}$
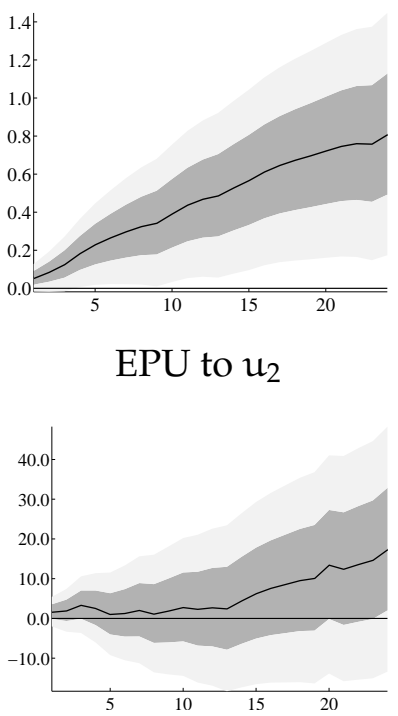

Note: The upper panel depicts the response of the VXO and SPREAD to a surprise innovation in business cycle uncertainty $\mathfrak{u}_{1}$ and oil and commodity price uncertainty $\mathfrak{u}_{2}$. The lower panel shows the responses for JLN and EPU to the same shocks. The response is calculated from a regression of the respective uncertainty measure on 24 lags of the two shock series $\mathfrak{u}_{1}$ and $u_{2}$. Confidence intervals are derived from a block bootstrap using block size 10 and 20000 replications. The dark shaded area indicates the \pm one standard deviation confidence interval while light grey represents the \pm two standard deviations confidence interval.

Figure I.1: Dynamic relation of VXO, SPREAD, JLN, and EPU 


\section{J Robustness: A three-factor model for uncertainty}

We review the robustness of the impulse responses of production using uncertainty indicators stemming from the factor model in (7) and (8) with $k=3$ common factors.

IP to $f_{1}$

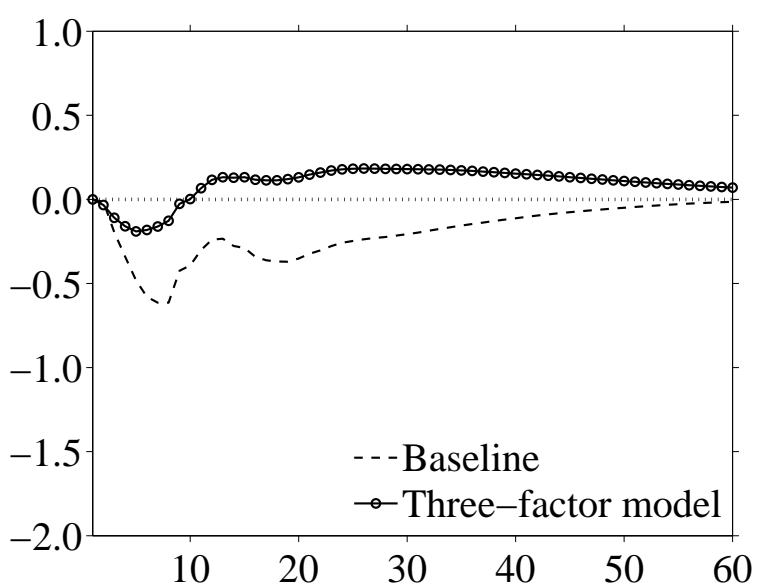

IP to $f_{2}$

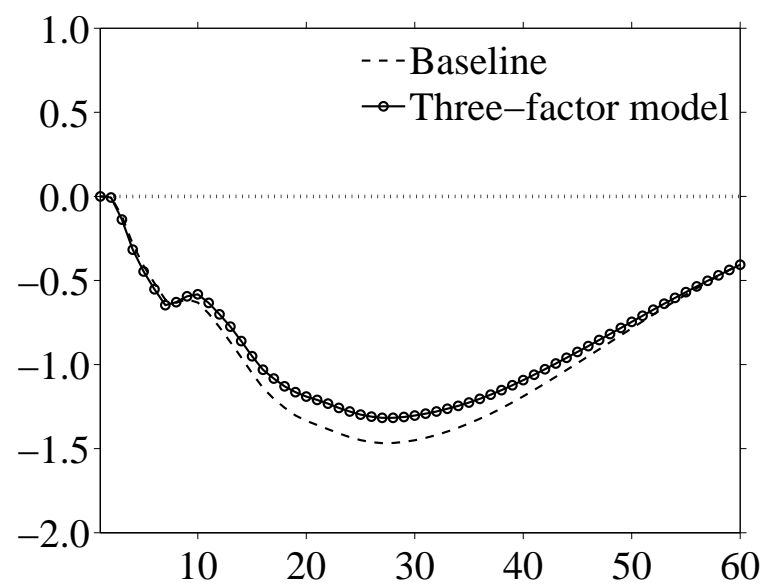

Note: This figure compares the baseline VAR to a VAR where uncertainty indicators are derived from a three factor model. The left panel depicts the response of IP following a sudden increase in $f_{1, t}$, and the right panel depicts the results for a sudden increase in $f_{2, t}$. The shock size is chosen to obtain an initial increase of macroeconomic uncertainty equal to its observed average monthly increase in the second half of 2008.

Figure J.1: Impulse response functions of IP using uncertainty indicators from a threefactor model 


\section{K Robustness: VAR results}

IP to $f_{1}$

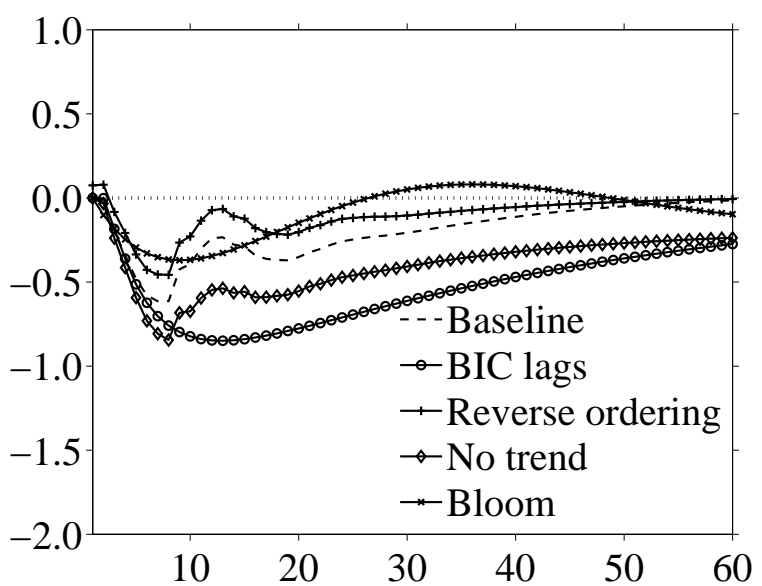

IP to $f_{2}$

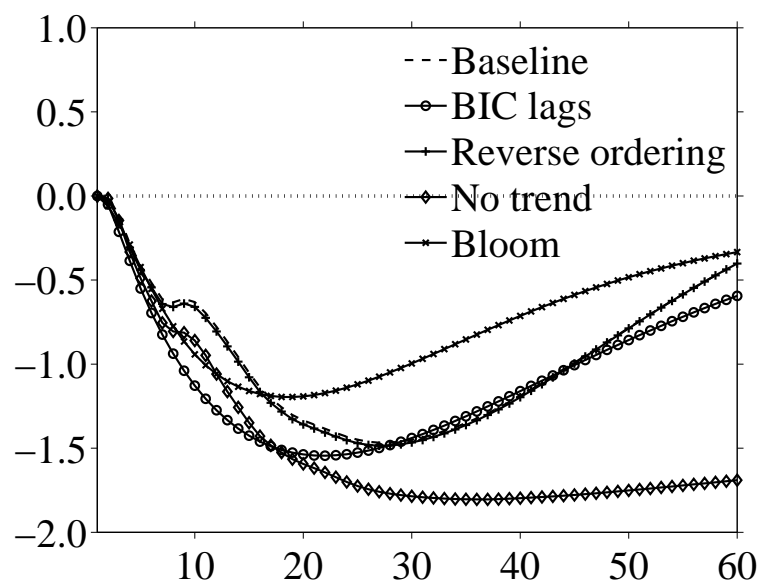

Note: The left panel depicts the response of IP following a sudden increase in business cycle uncertainty for different VAR systems, and the right panel depicts the response of IP to a sudden increase in oil and commodity price uncertainty. Along with our baseline results, a number of robustness checks are shown. First, we choose the lag-length by the BIC (BIC lags). Second, we revert the ordering of the variables in the VAR (Reverse ordering). Third, we remove the linear trend from the specification (No trend). Fourth, we consider a eight-variable VAR in the spirit of Bloom (2009) which includes IP, E, Hours, CPI, hourly wages, the federal funds rate, $f_{\bullet}, S \& P 500$ share price index (Bloom). All variables except the federal funds rate enter in logs. The shock size is chosen to obtain an initial increase of macroeconomic uncertainty equal to its observed average monthly increase in the second half of 2008.

Figure K.1: Impulse response functions of IP for different VARs 


\section{Robustness: Both types of macroeconomic uncertainty in the VAR}

In section 4.4, the VARs comprise only one type of macroeconomic uncertainty, i.e. we do not control for the effects of the other type. Table L.1 provides a forecast error variance decomposition for VARs which contain both uncertainty indicators. Since theory does not provide guidance on how to reasonably order the variables in such a VAR, we present results for two different orderings which both rely on the assumption that real activity reacts with a lag to surprise increases in macroeconomic uncertainty. The first ordering assumes, however, that business cycle uncertainty reacts with a lag to oil and commodity price uncertainty while business cycle uncertainty may affect oil and commodity price uncertainty instantaneously, i.e. we control for innovations in business cycle uncertainty when analyzing the effects of oil and commodity price uncertainty on real activity. Those results are given in the left part of table L.1. The second ordering presented in the right part of table L.1 reverses the two types of uncertainty, i.e. we control for innovations in oil and commodity price uncertainty when analyzing the effects of business cycle uncertainty. Table L.1 reveals that surprise increases in oil and commodity price uncertainty are more important for real activity than those to business cycle uncertainty even if we use this larger VAR.

\begin{tabular}{|c|c|c|c|c|c|c|c|c|c|c|c|c|}
\hline \multirow[b]{3}{*}{ Horizon } & \multicolumn{6}{|c|}{ Ordering: $\left[Y_{\bullet} f_{1} f_{2}\right]^{\prime}$} & \multicolumn{6}{|c|}{ Ordering: $\left[Y_{\bullet} f_{2} f_{1}\right]^{\prime}$} \\
\hline & \multicolumn{2}{|c|}{ IP } & \multicolumn{2}{|c|}{$\mathrm{CU}$} & \multicolumn{2}{|c|}{ Hours } & \multicolumn{2}{|c|}{ IP } & \multicolumn{2}{|c|}{$\mathrm{CU}$} & \multicolumn{2}{|c|}{ Hours } \\
\hline & $f_{1}$ & $f_{2}$ & $f_{1}$ & $f_{2}$ & $f_{1}$ & $f_{2}$ & $f_{1}$ & $f_{2}$ & $f_{1}$ & $f_{2}$ & $f_{1}$ & $f_{2}$ \\
\hline 12 & 1.42 & 3.65 & 2.92 & 2.47 & 1.16 & 6.47 & 0.52 & 4.54 & 1.46 & 3.93 & 0.37 & 7.27 \\
\hline 24 & 0.96 & 13.79 & 5.99 & 11.12 & 3.06 & 17.39 & 0.44 & 14.30 & 2.04 & 15.07 & 0.44 & 20.01 \\
\hline 36 & 1.00 & 21.81 & 9.24 & 16.42 & 4.72 & 22.03 & 0.53 & 22.28 & 3.16 & 22.50 & 0.79 & 25.96 \\
\hline 60 & 1.28 & 26.28 & 10.26 & 16.42 & 5.28 & 22.36 & 0.52 & 27.05 & 3.93 & 22.75 & 1.08 & 26.56 \\
\hline
\end{tabular}

Note: This table presents the share of the forecast error variance (\%) due to innovations in business cycle uncertainty $\left(f_{1}\right)$ and oil and commodity price uncertainty $\left(f_{2}\right)$. The shares are obtained from trivariate VARs with 12 lags consisting of one measure of economic activity and both types of macroeconomic uncertainty. Shocks are orthogonalized using a recursive ordering. Rows contain results for different forecast horizons.

Table L.1: Forecast error variance in a VAR comprising both types of uncertainty 


\section{Robustness: FEVD using the VAR in Bloom (2009)}

\begin{tabular}{rrrrrrrrr}
\hline & \multicolumn{3}{c}{$\begin{array}{c}\text { Business cycle } \\
\text { uncertainty }\end{array}$} & & \multicolumn{3}{c}{$\begin{array}{c}\text { Oil and commodity } \\
\text { price uncertainty }\end{array}$} \\
\cline { 2 - 3 } \cline { 7 - 8 } Horizon & IP & Employment & Hours & & IP & Employment & Hours \\
\hline 12 & 2.72 & 4.94 & 5.79 & & 10.31 & 7.00 & 5.02 \\
24 & 1.57 & 5.74 & 6.27 & & 15.90 & 13.87 & 6.39 \\
36 & 1.05 & 5.35 & 6.04 & & 16.33 & 14.99 & 6.05 \\
60 & 0.83 & 6.21 & 6.01 & & 15.91 & 14.23 & 6.19 \\
\hline
\end{tabular}

Note: This table presents the share of the forecast error variance (\%) due to business cycle uncertainty (left panel) and oil and commodity price uncertainty (right panel). The shares are obtained from VARs including eight variables as in Bloom (2009) with lag length selected by BIC. The ordering of the variables is: IP, employment, Hours, CPI, hourly wages, federal funds rate, macroeconomic uncertainty, S\&P 500 Stock prices. All variables except for the interest rate enter in log-levels. For better comparability, results are documented only for real activity variables. Rows contain results for different forecast horizons.

Table M.1: FEVD using the VAR in Bloom (2009) 